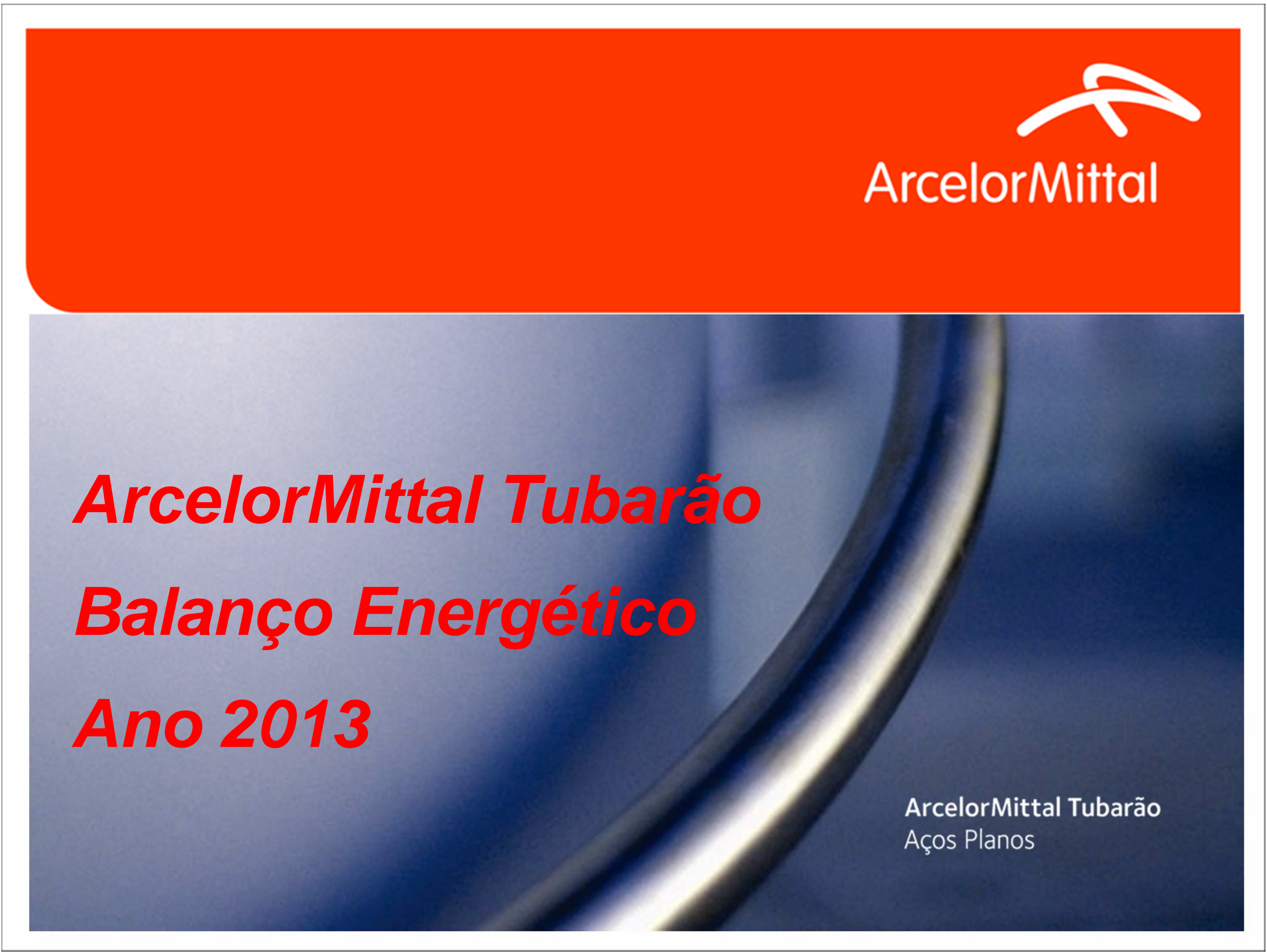




\section{Fatos Relevantes}

- Produção anual de 4.491.854 t de aço bruto - produção estável em relação à 2012.

- Produção anual de Bobinas Laminadas a Quente de 3.726.871 t 7,8\% de elevação em relação a 2012.

- Unidades Geradoras da Central Termelétrica em manutenção aproveitando período de menor produção relacionado à parada do Alto Forno 3.

- Redução relevante na geração de energia elétrica interna devido menor disponibilidade de combustíveis (off-gas) e redução de produção na Sol Coqueria adequando à demanda de coque do grupo ArcelorMittal Brasil. 


\section{Fluxograma Resumido de Produção}

\section{t/ano NDam $3 / a n o$}

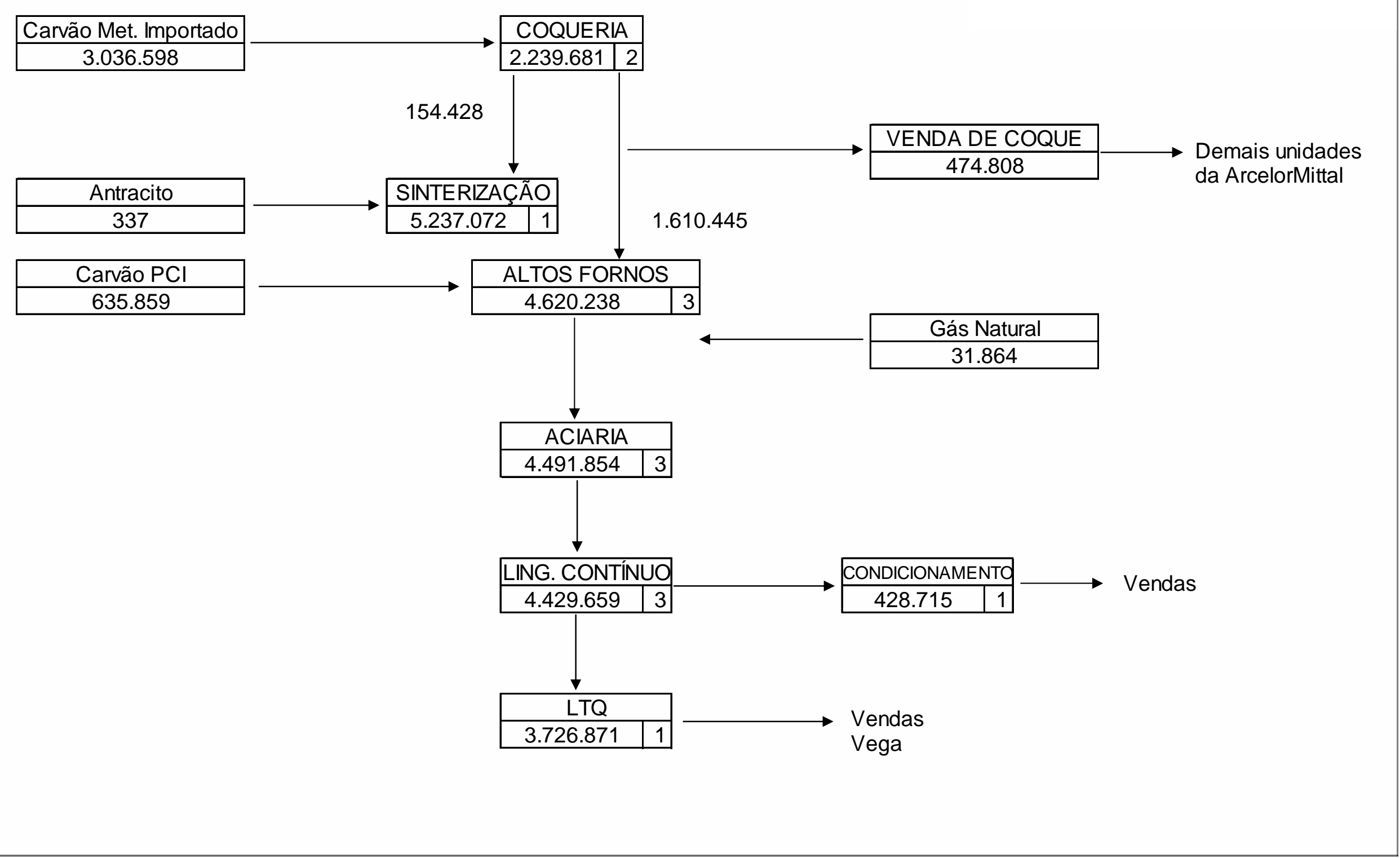




\section{Consumo de Energia Primária}

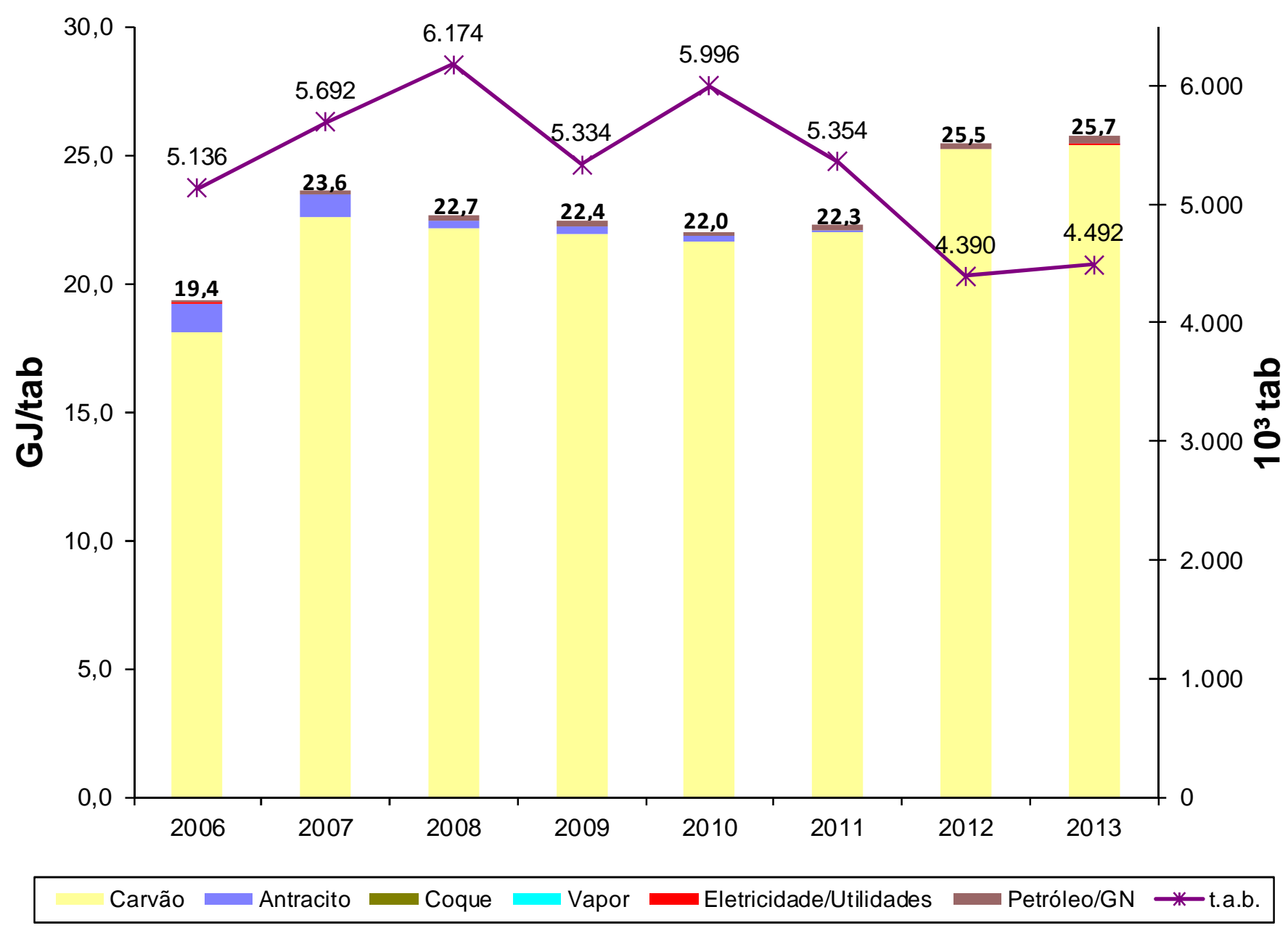

- Consumo energético global de $25,7 \mathrm{GJ} / \mathrm{tab}$ - aumento de $0,8 \%$ em relação a 2012 . A manutenção do alto valor de consumo de energia primária está relacionado à operação down stream da usina em marcha reduzida demandando uma grande quantidade de energia com uma menor produção de aço. 
Consumo de Energia Primária por Processos

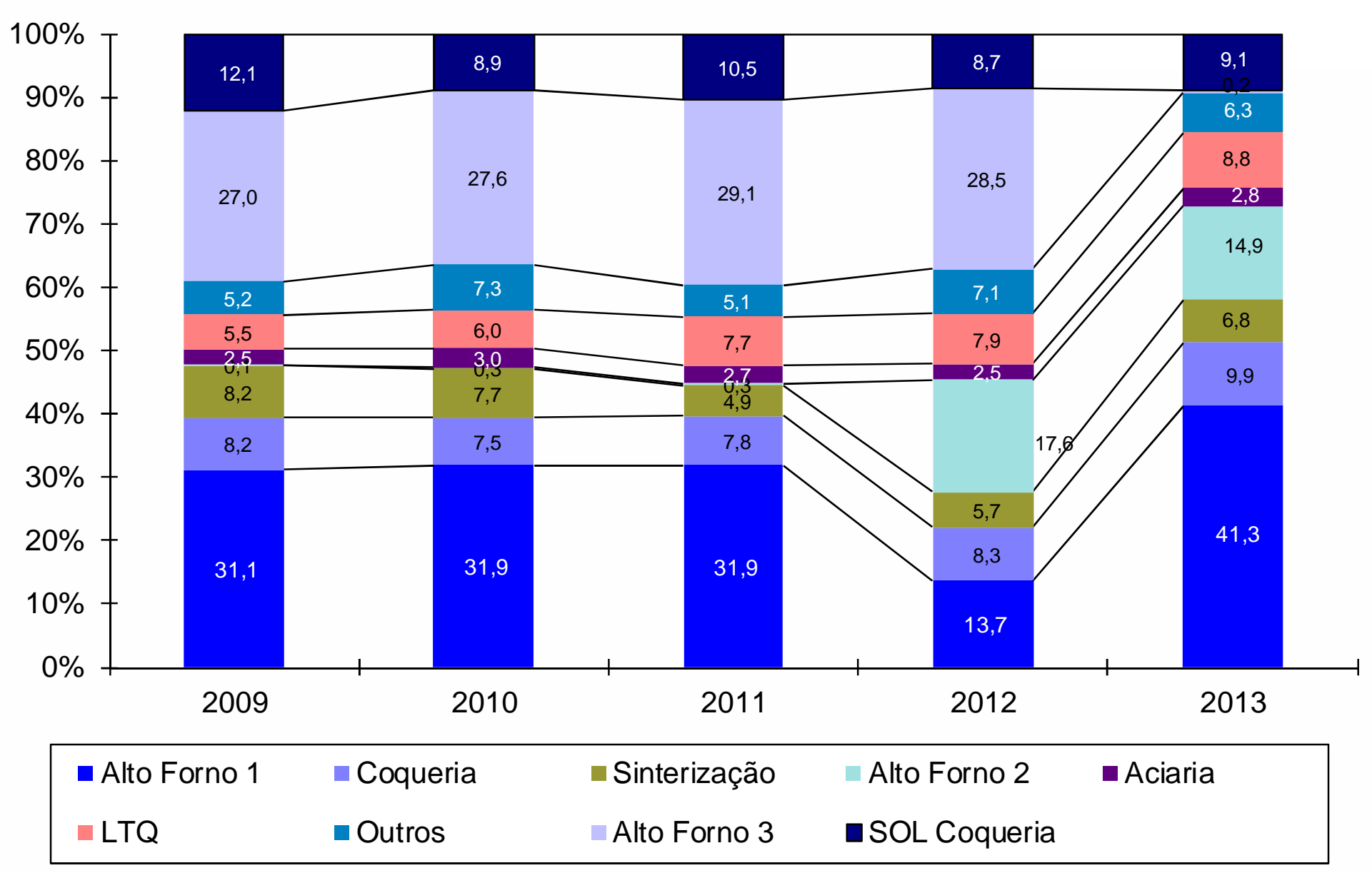

- Redistribuição de consumo percentual refletindo a operação de somente dois altos fornos no ano de 2013. 


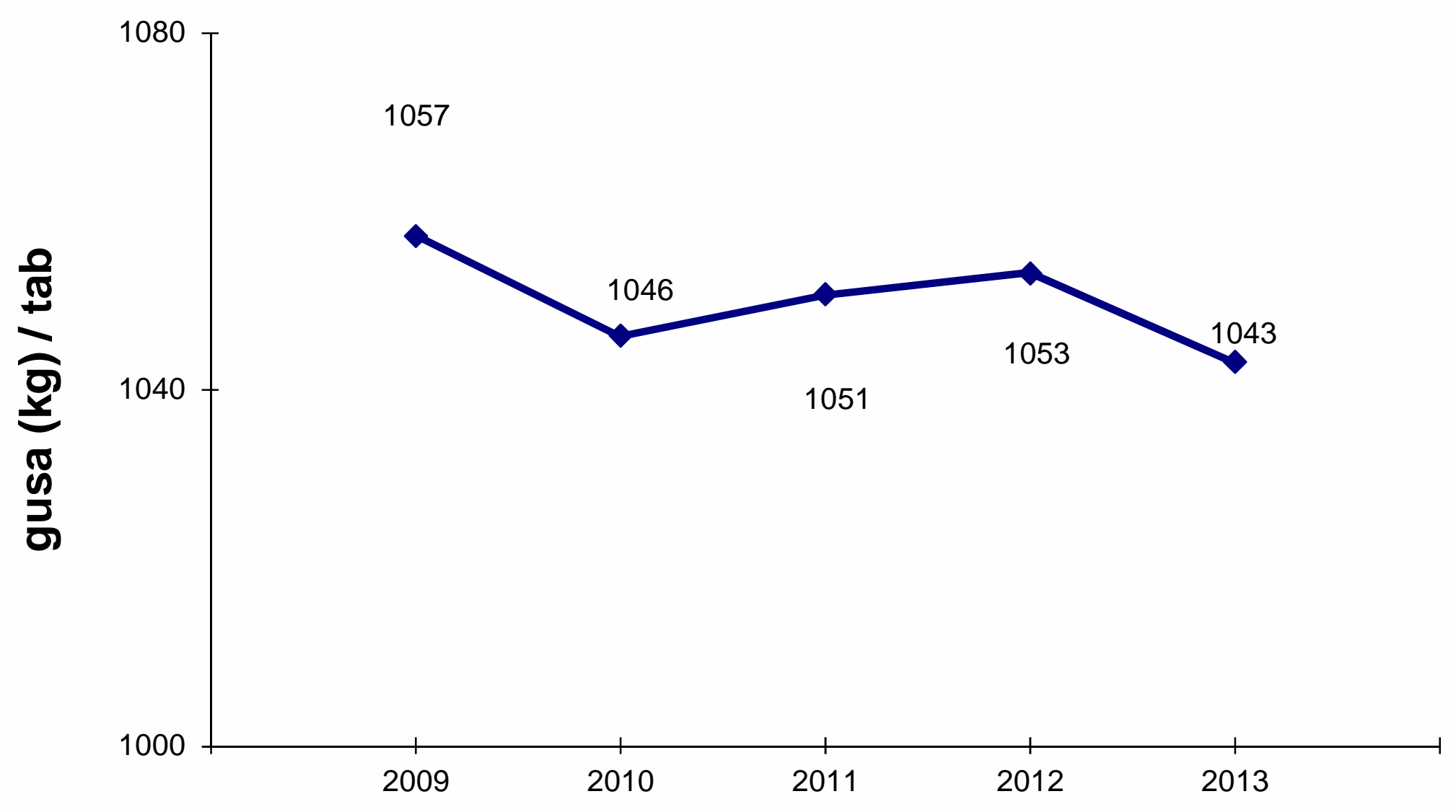

Melhor rendimento devido operação estável dos Altos Fornos. 


\section{Consumo de Combustíveis nos Altos Fornos}

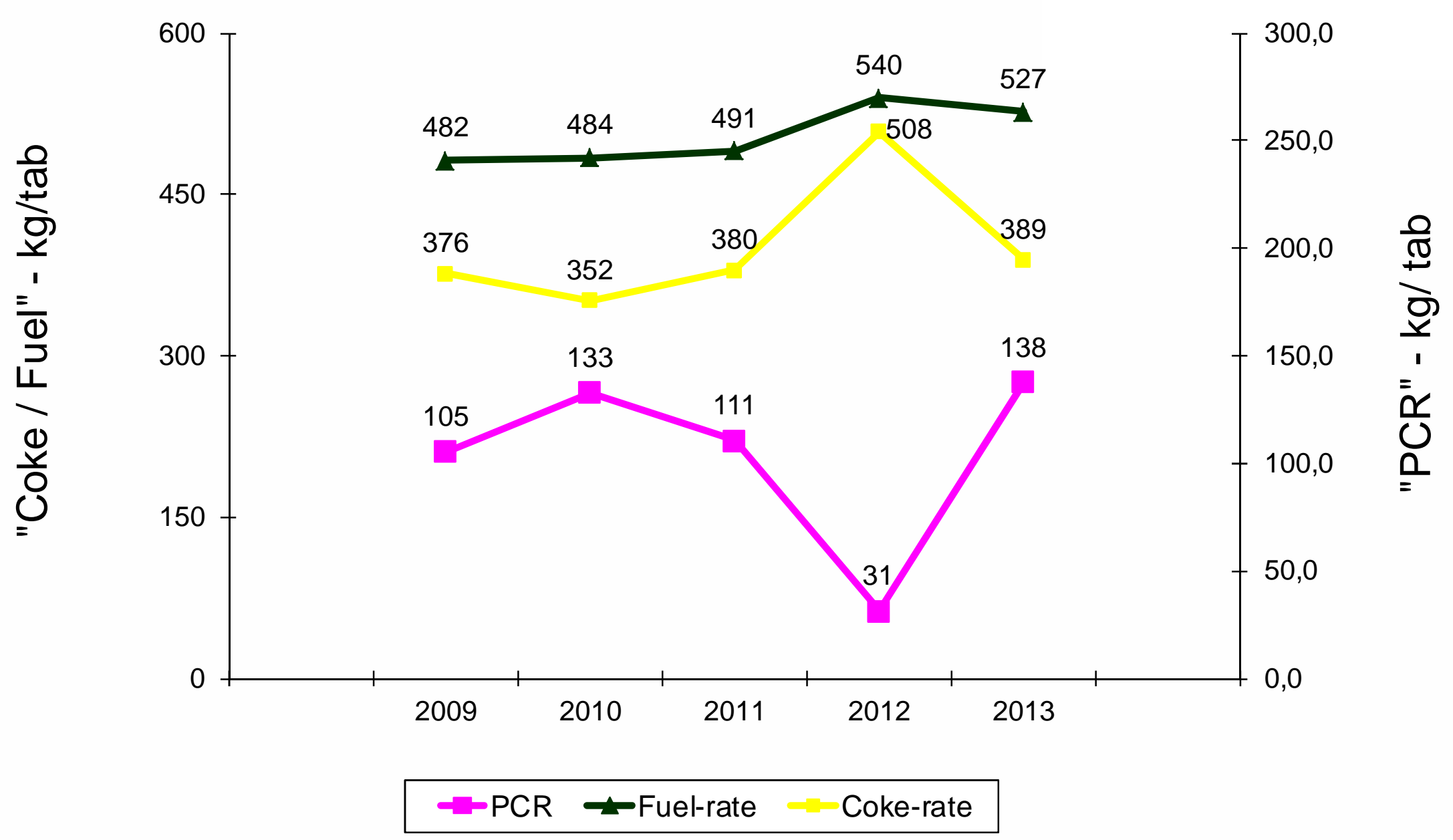

Normalização dos valores de consumo nos Altos Fornos devido operação estável dos Altos Fornos. 


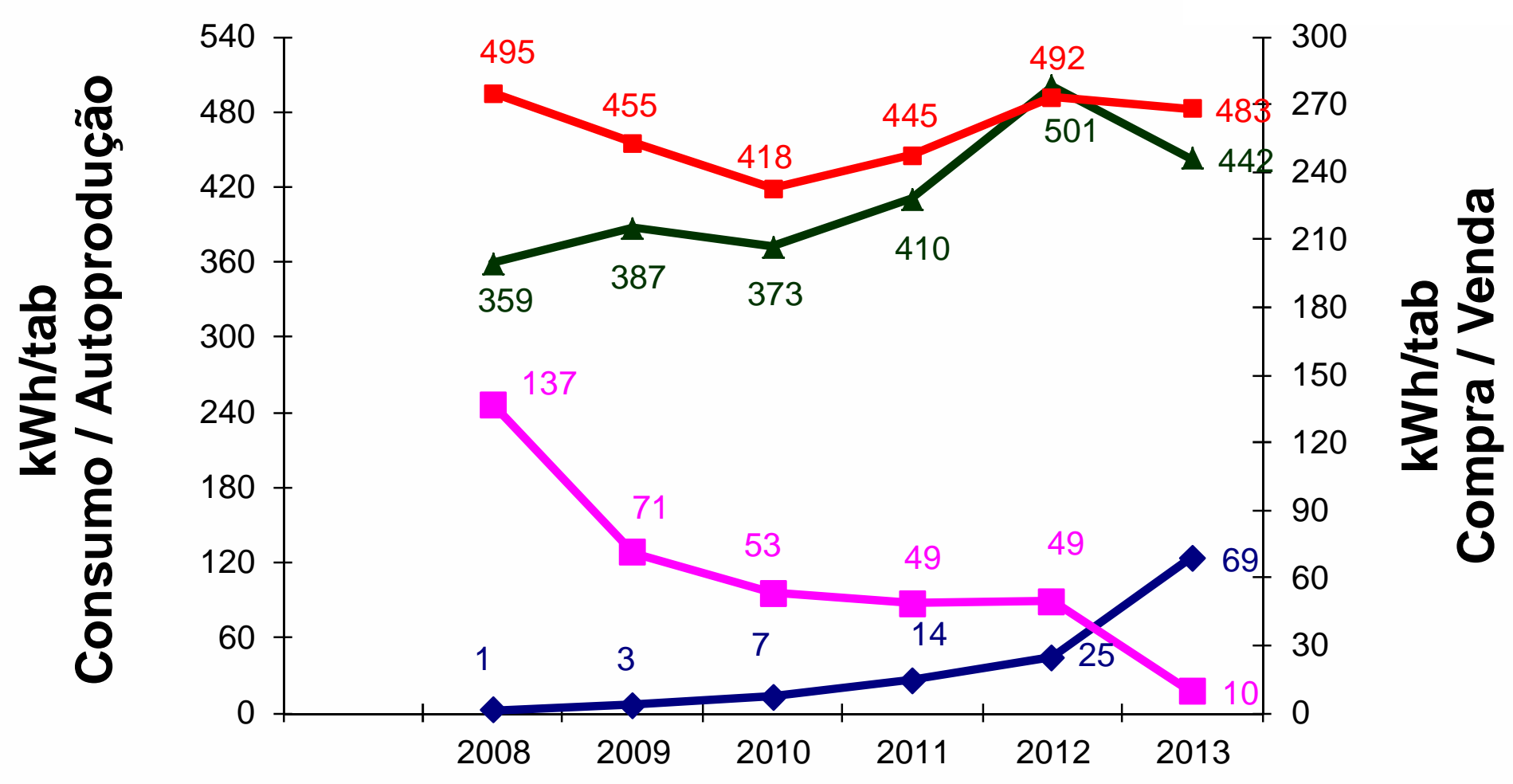

$\leftarrow$ Demanda $\rightarrow$-Geração $\rightarrow$ Compras $\rightarrow$-Vendas

- Redução na geração específica devido redução de produção na Sol Coqueria.

- Redução de consumo específico devido estabilidade operacional (sem grandes paradas de áreas).

- Aumento da compra de energia elétrica devido a menor disponibilidade de gases para as termoelétricas. 


\section{Consumo de Energia Elétrica por Processo}

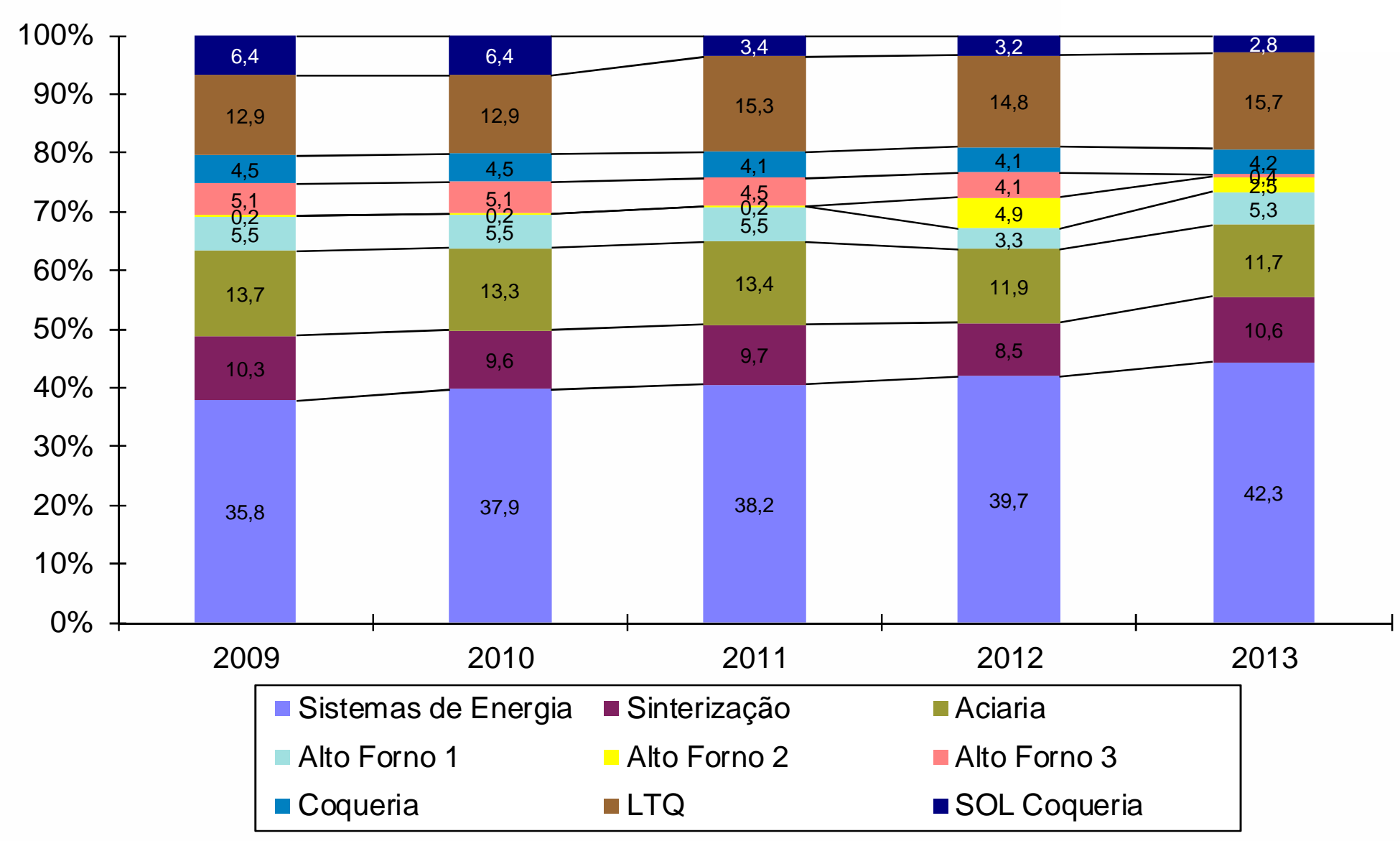

- Não houve variações significativas no consumo de energia elétrica em termos percentuais por área, apenas a parada do Alto Forno 3. 


\section{Demanda de Energia Elétrica da Usina}

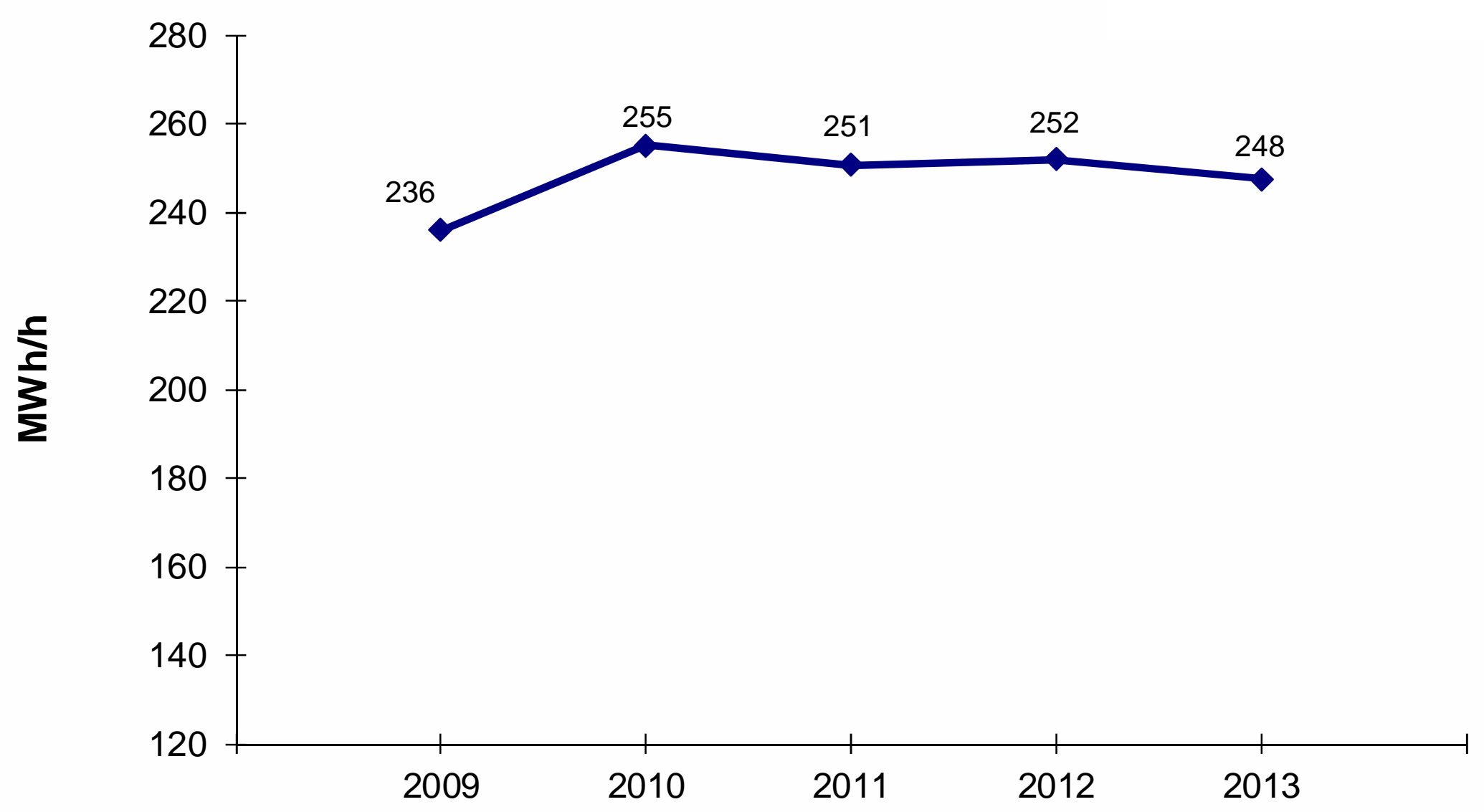

Sem variações significativas. 


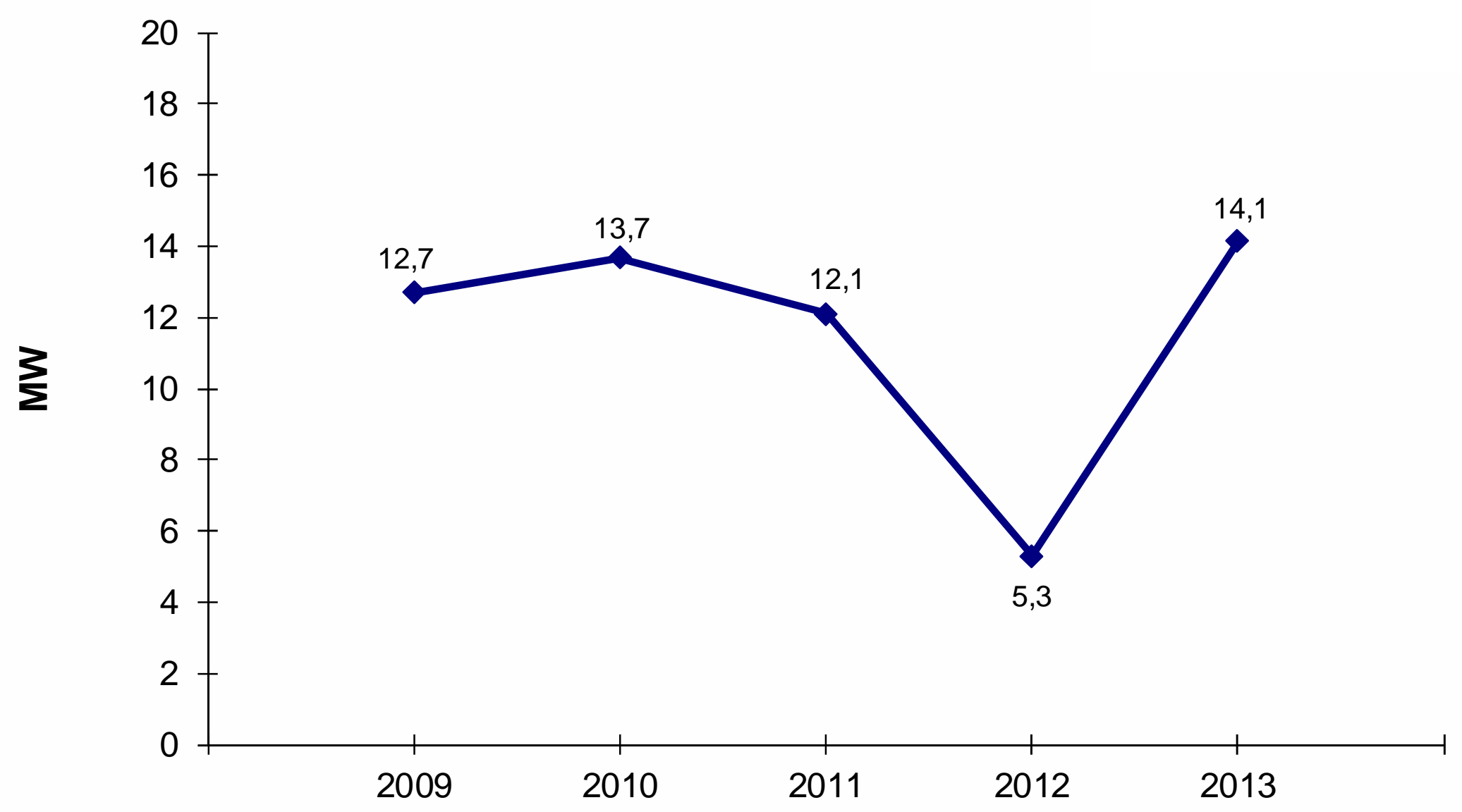

- Recuperação da geração da TRT após reforma da máquina e retorno operacional AF\#1. 


\section{Perdas de GCO, GAF e GAC}

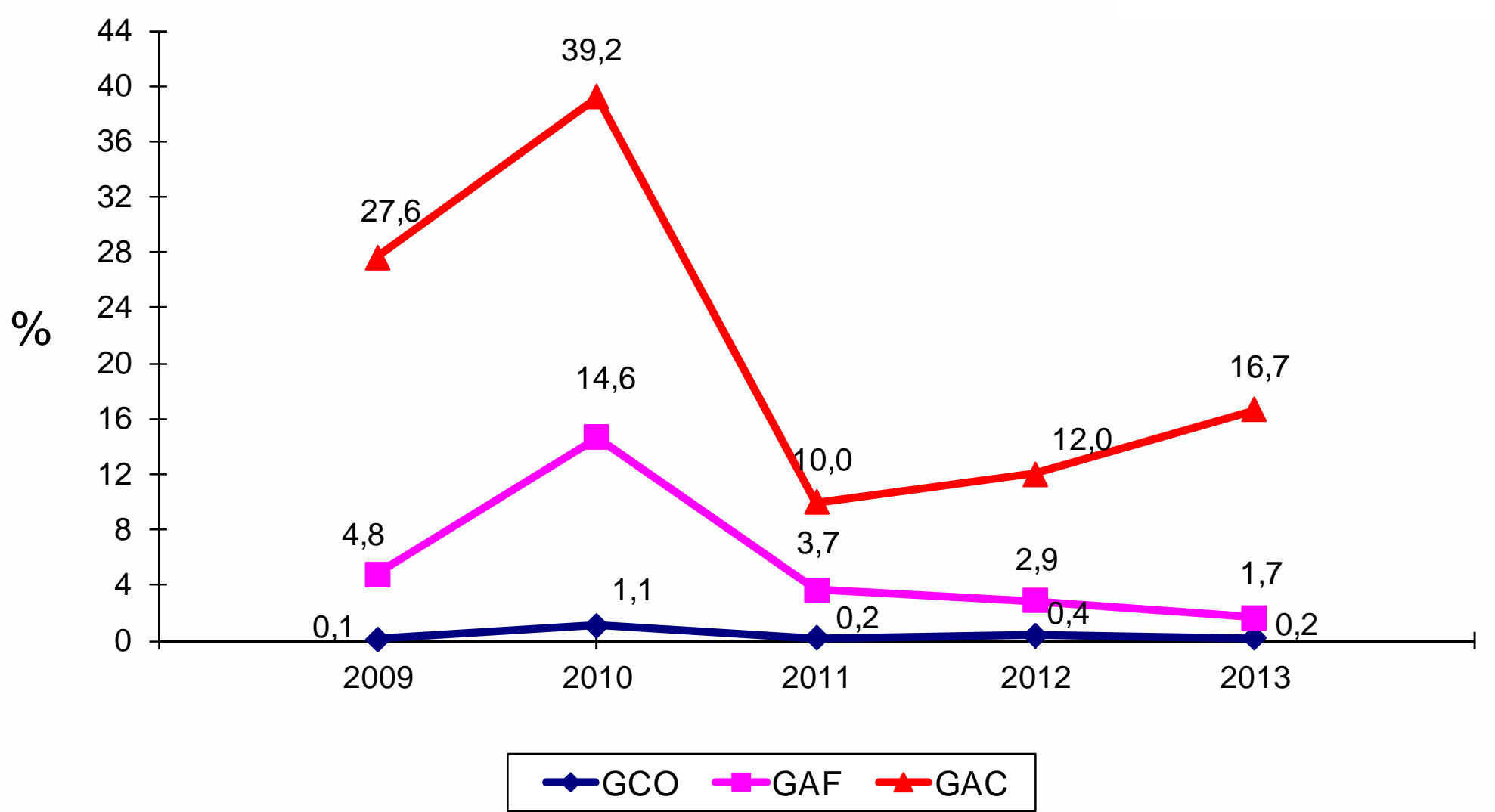

- Mudança de patamar de recuperação do Gás de Aciaria devido maximização de utilização no laminador de tiras à quente em detrimento ao uso nas termelétricas, compensado com a utilização dos gases de Coqueria e Alto Forno. 


\section{Aproveitamento global de Combustíveis}

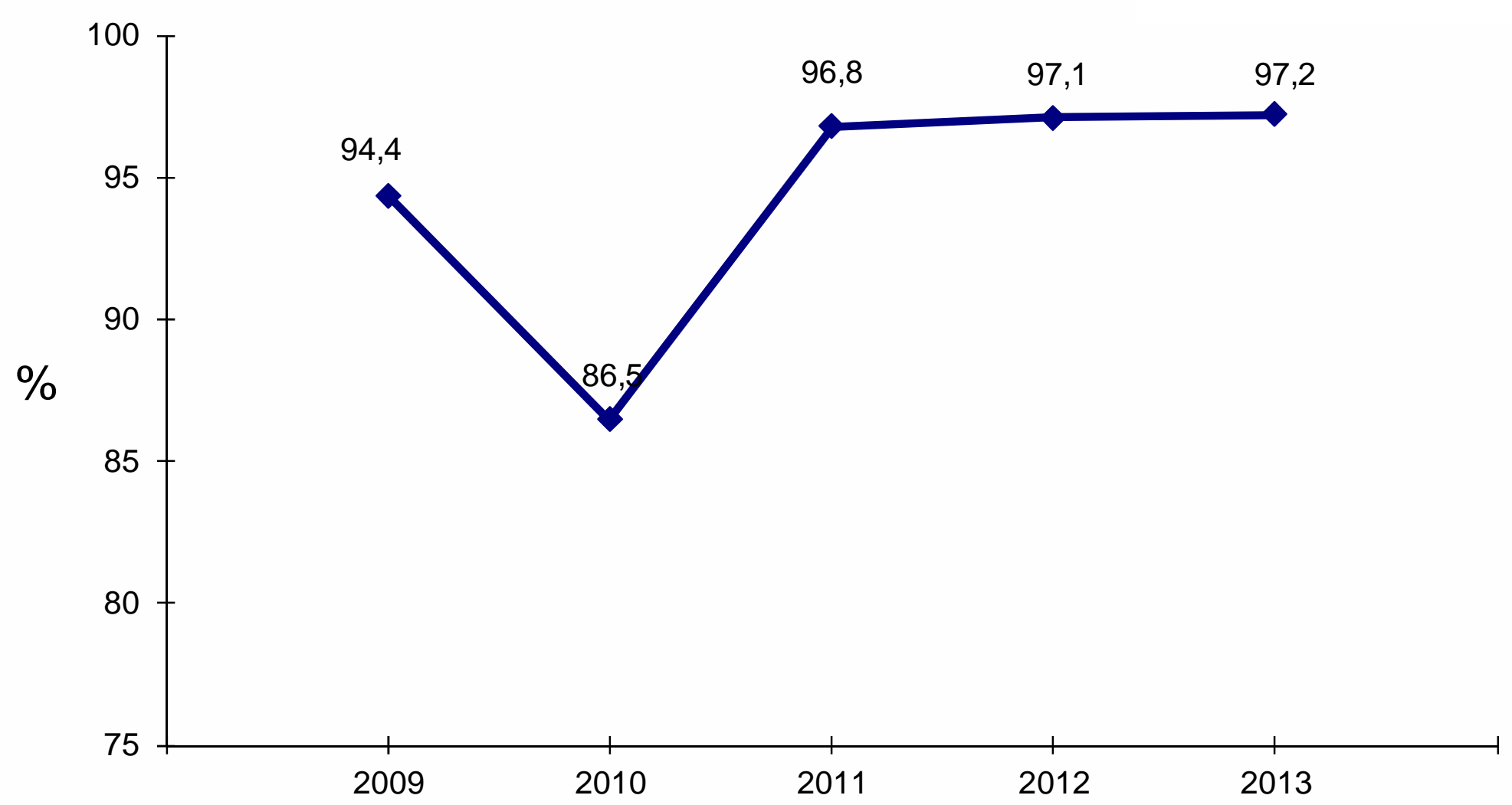

-Melhor aproveitamento de gases nos processos e centrais termoelétricas. 


\section{Consumo de GCO por Processo}

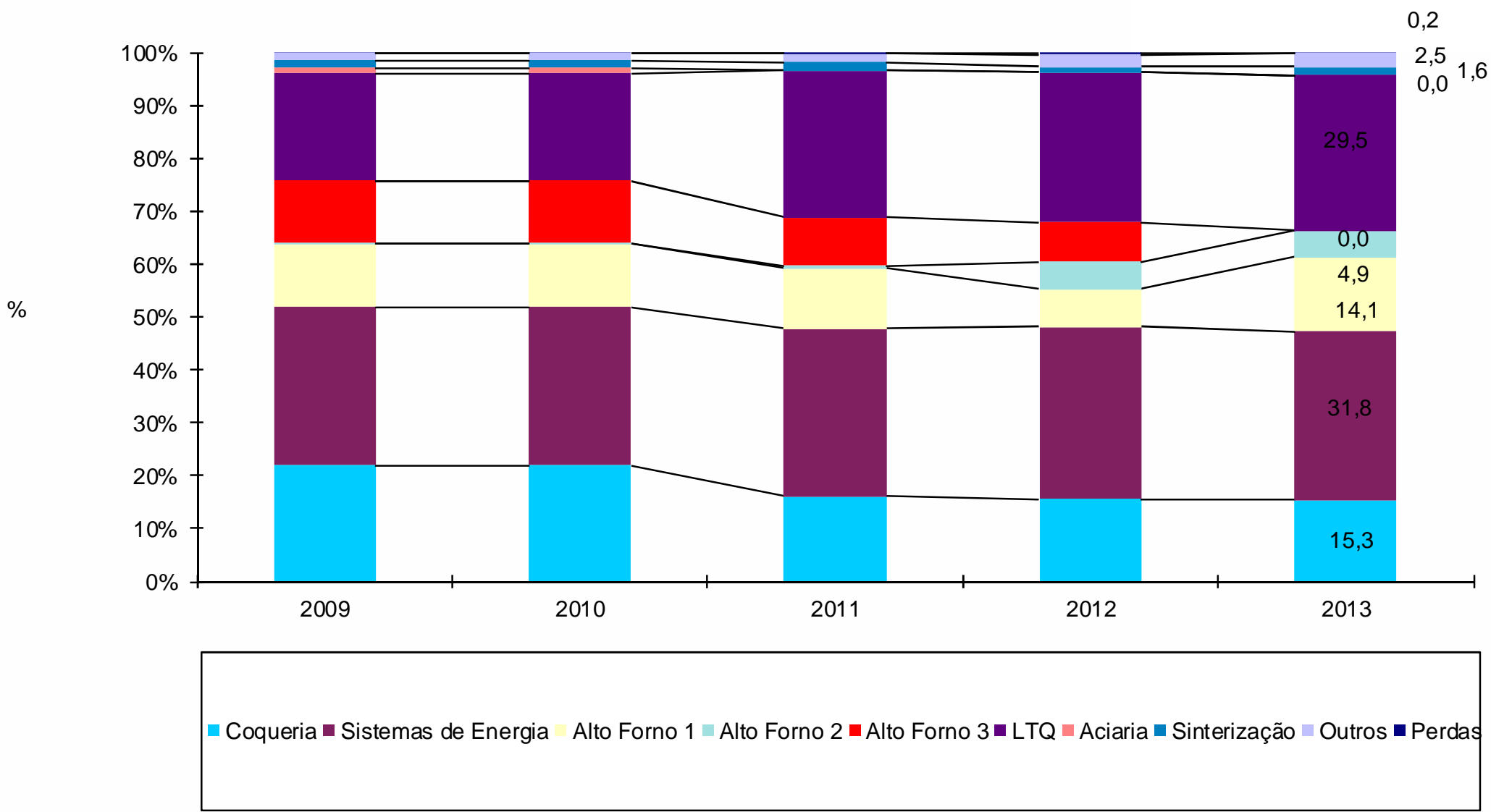

- Não houve variações significativas no consumo de Gás de Coqueria em termos percentuais por área, apenas a parada do Alto Forno 3 e retorno Alto Forno 1. 


\section{Consumo de GAF por Processo}

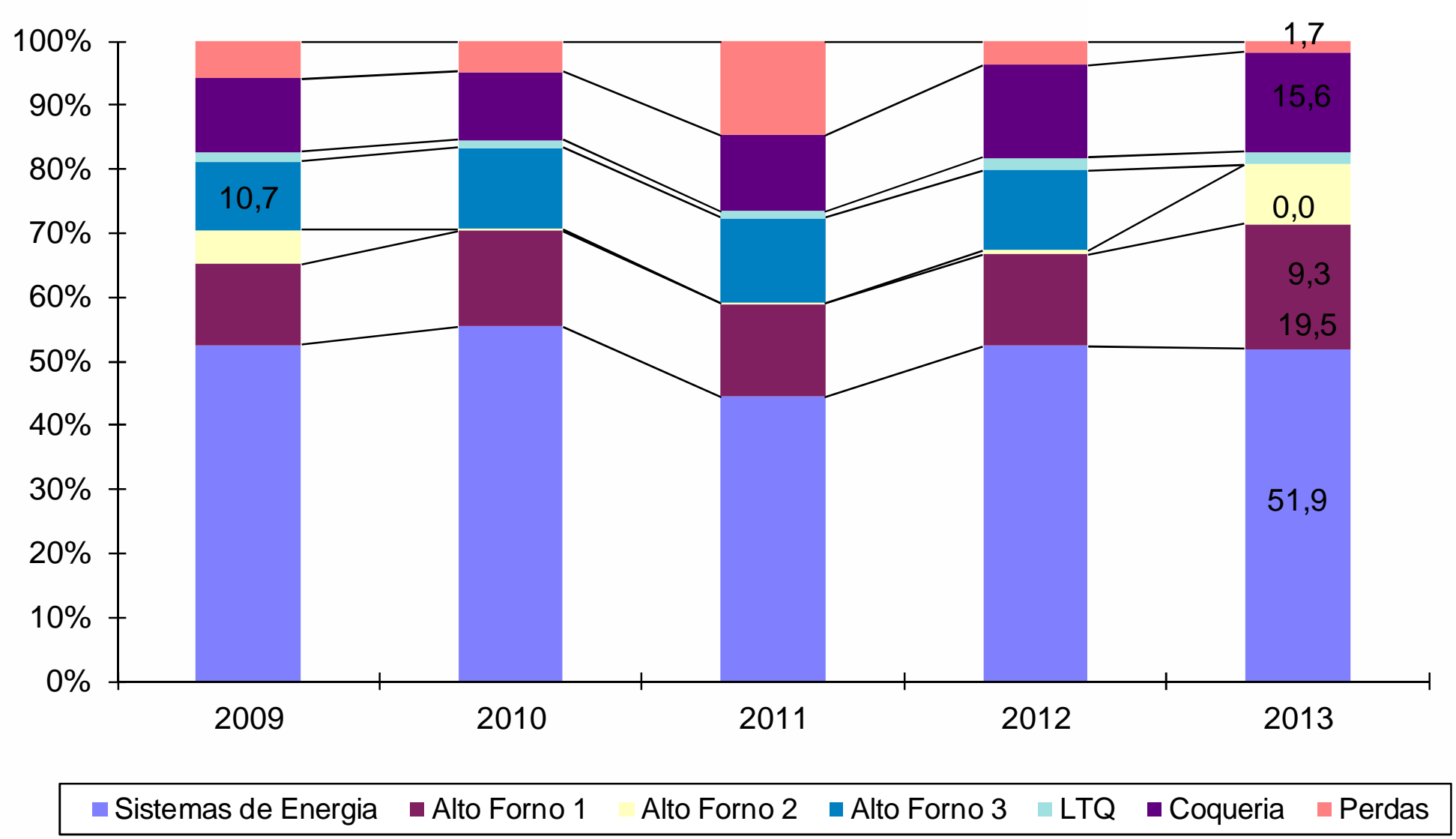

- Não houve variações significativas no consumo de Gás de Alto Forno em termos percentuais por área, apenas ressaltando a parada do Alto Forno $3 \mathrm{e}$ retorno Alto Forno 1. 


\section{Consumo de GAC por processo}

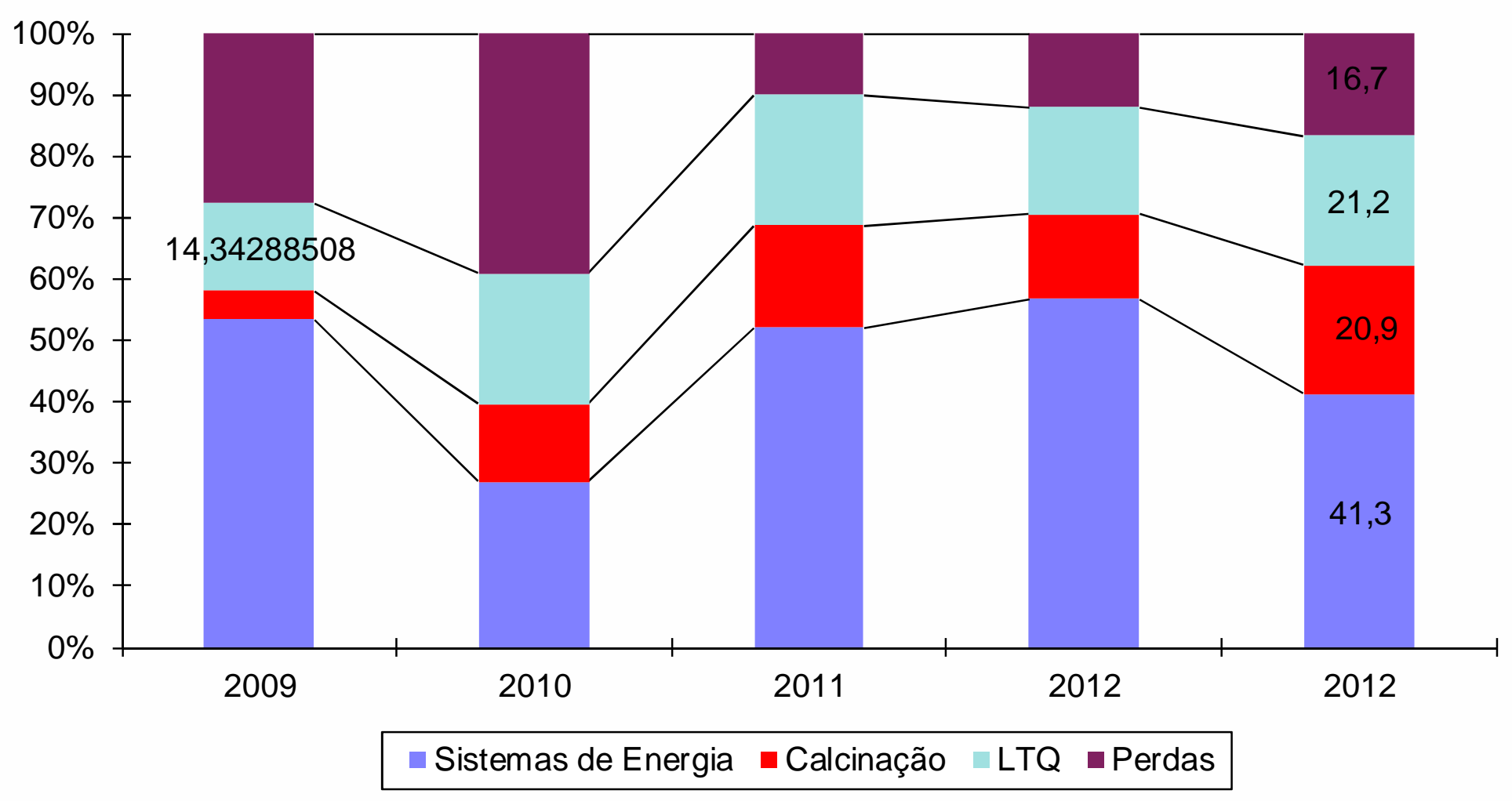

- Menor recuperação de gás de Aciaria nas Centrais Termelétrica, aumentando seu aproveitamento no laminador de tiras à quente. 


\section{Consumo global de gases combustíveis}

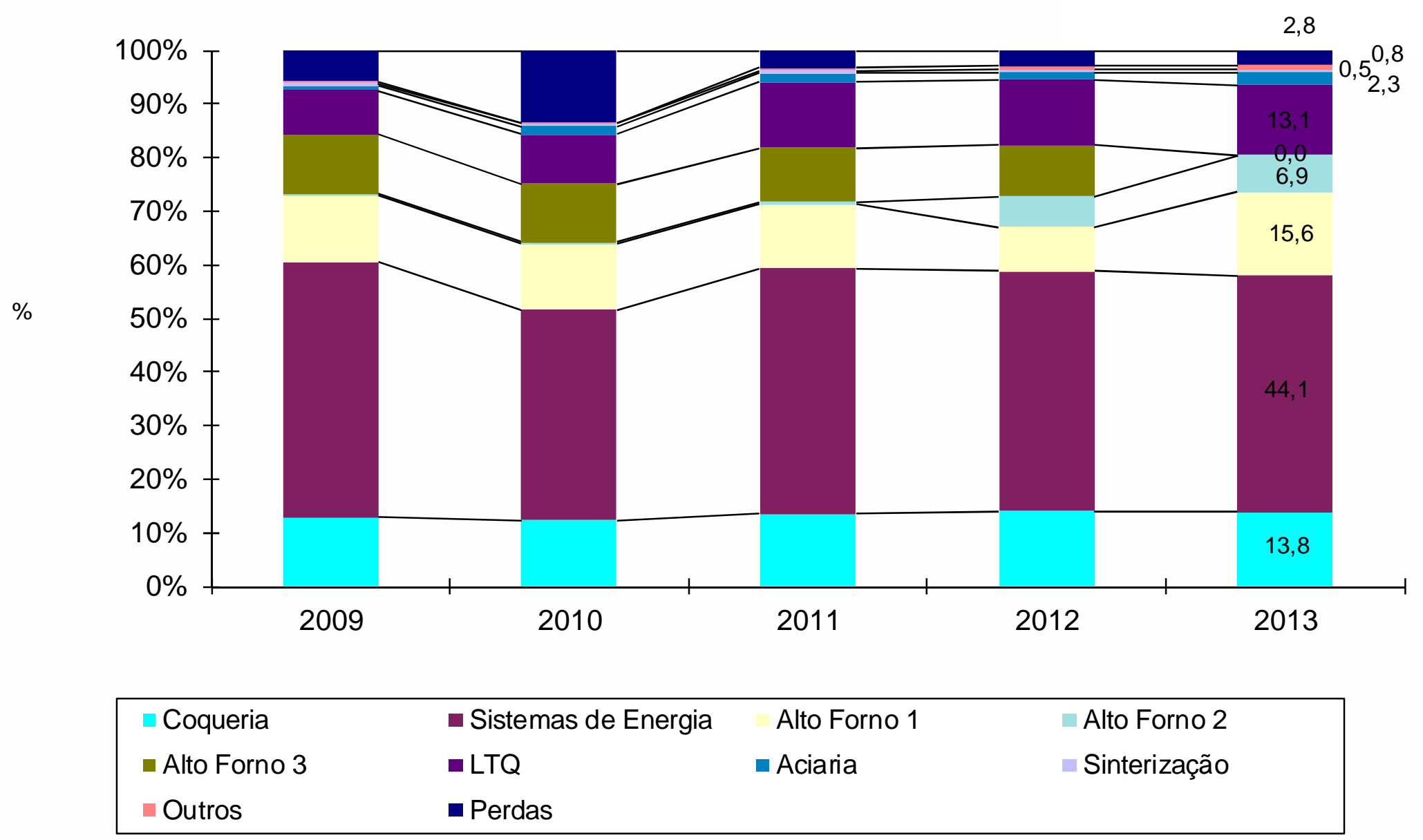

- Sem comentários relevantes, ressaltando somente a parada do Alto Forno 3 e retorno Alto Forno 1. 
Consumo de combustíveis suplementares

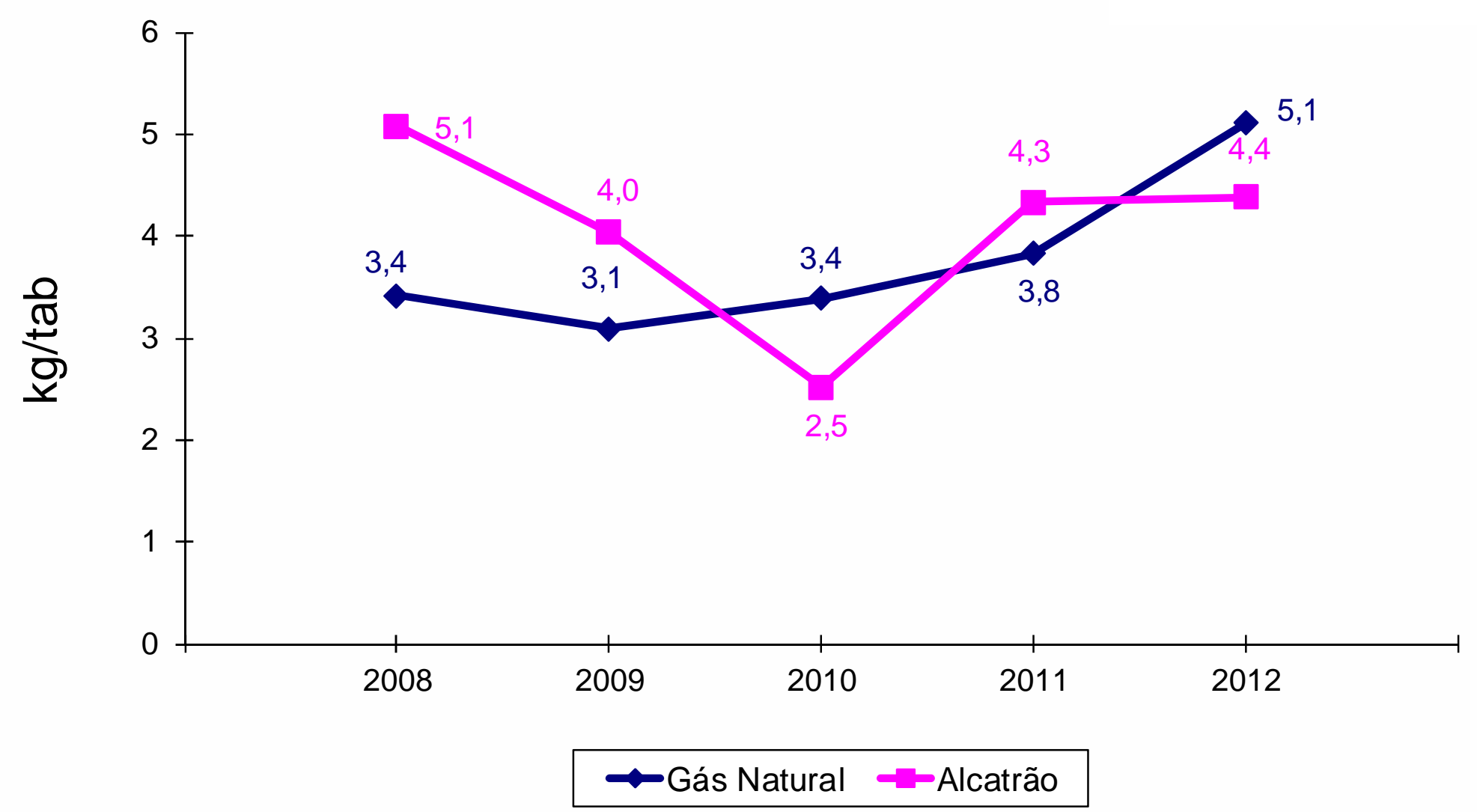

- Complementação dos combustíveis suplementares para a usina em função de menor produção de combustíveis (redução da produção de Gusa). 


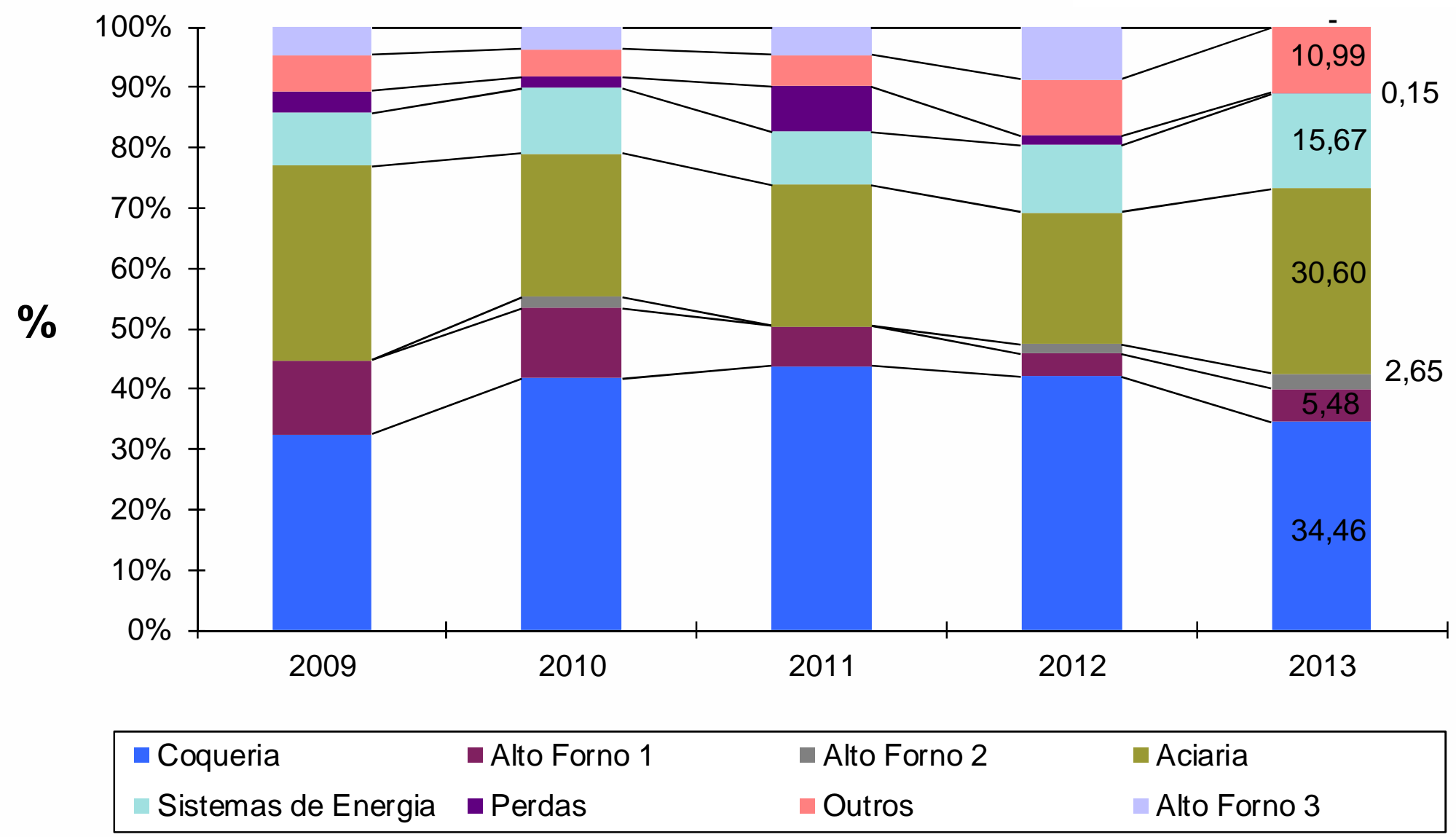

- Sem comentários relevantes, ressaltando somente a parada do Alto Forno 3 e redução de consumo na coqueria (substituição equipamentos turbinados à vapor). 


\section{Consumo de Oxigênio}

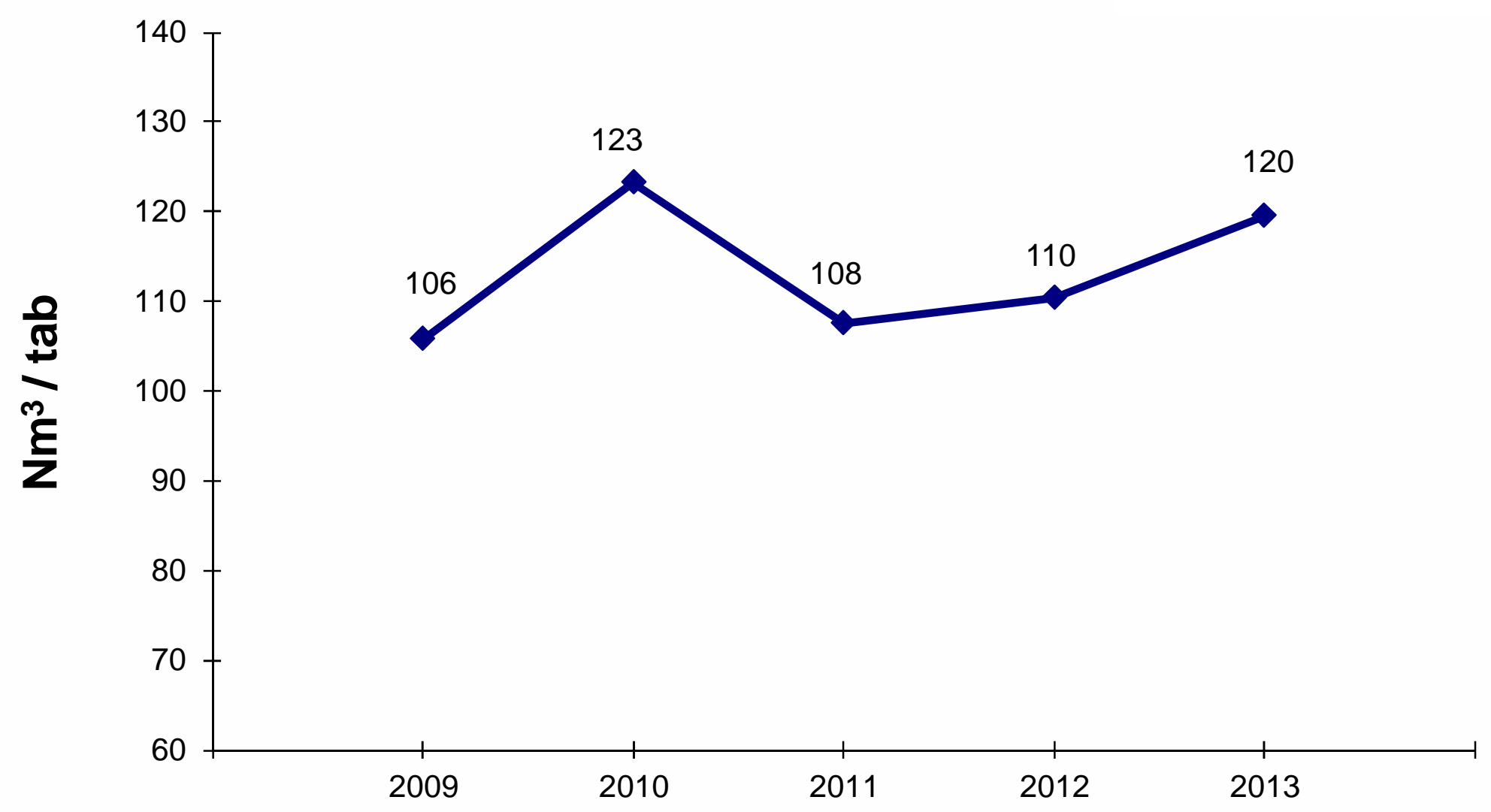

- Elevação do consumo de O2 acompanhando maior injeção no AF 1. 


\section{Perdas de Oxigênio}

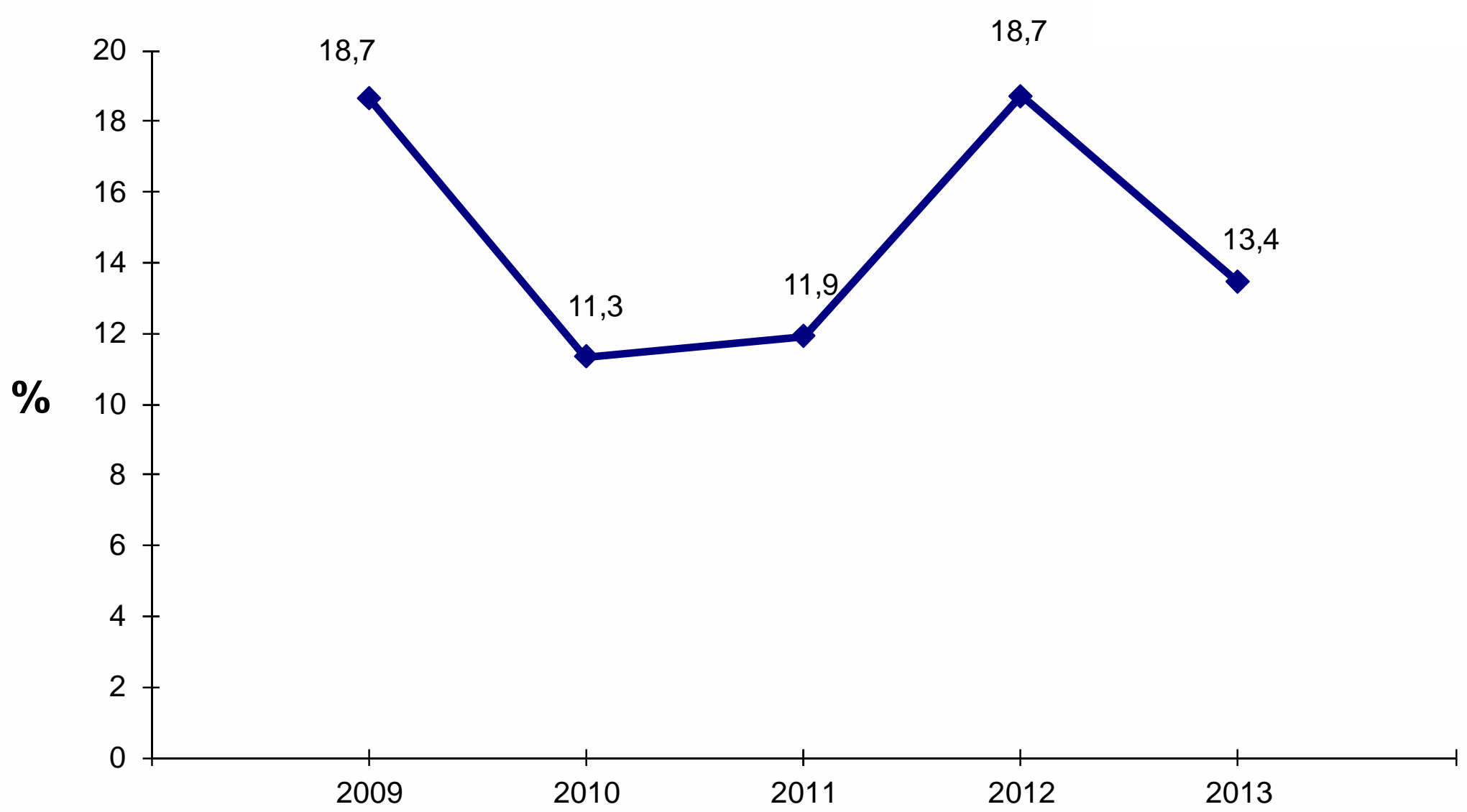

Normalização da perda de $\mathrm{O}_{2}$ conforme variações de consumo dos AFs. 


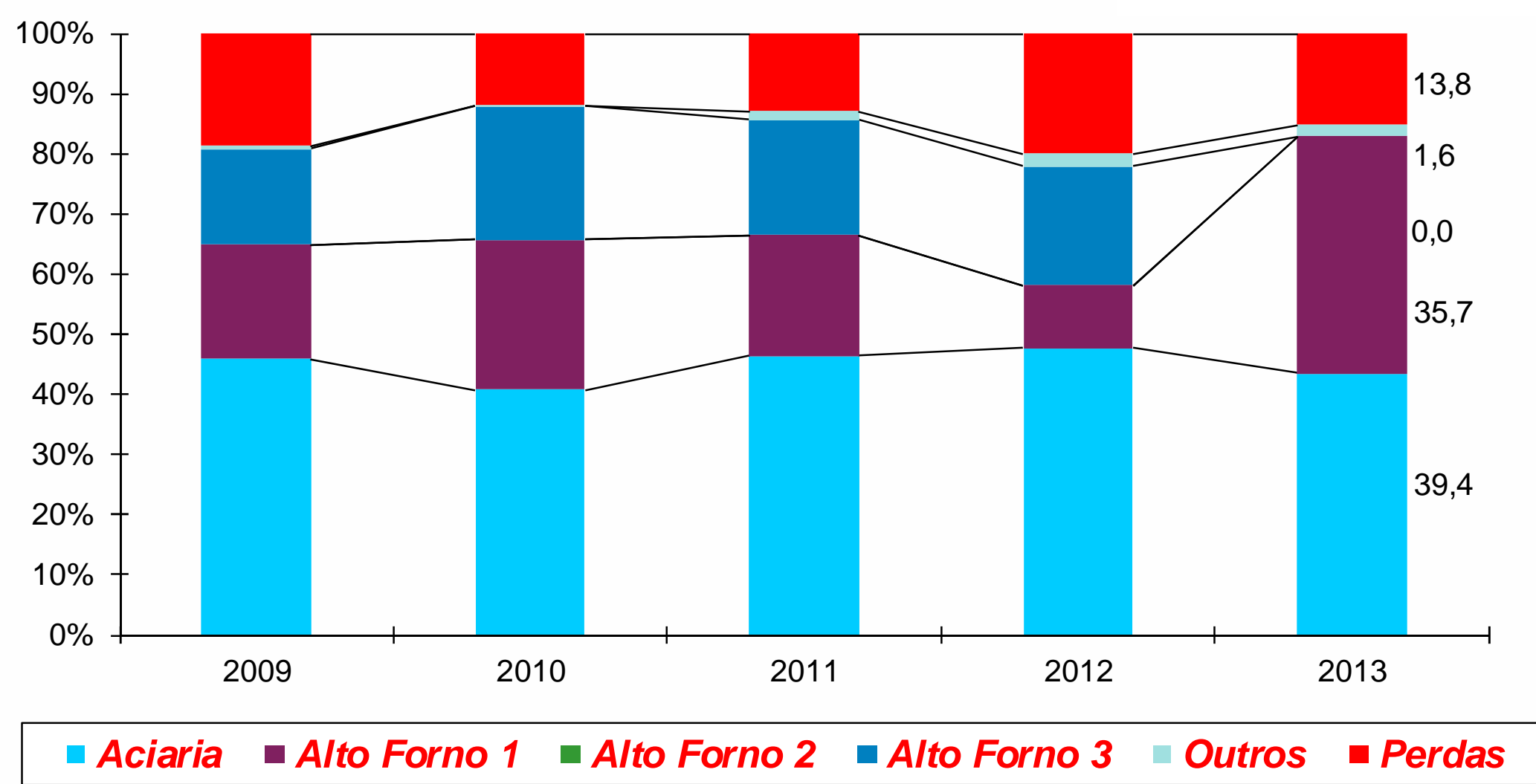

- Ressaltando a parada de consumo do AF3 e elevação de consumo no AF1 pós reforma. 


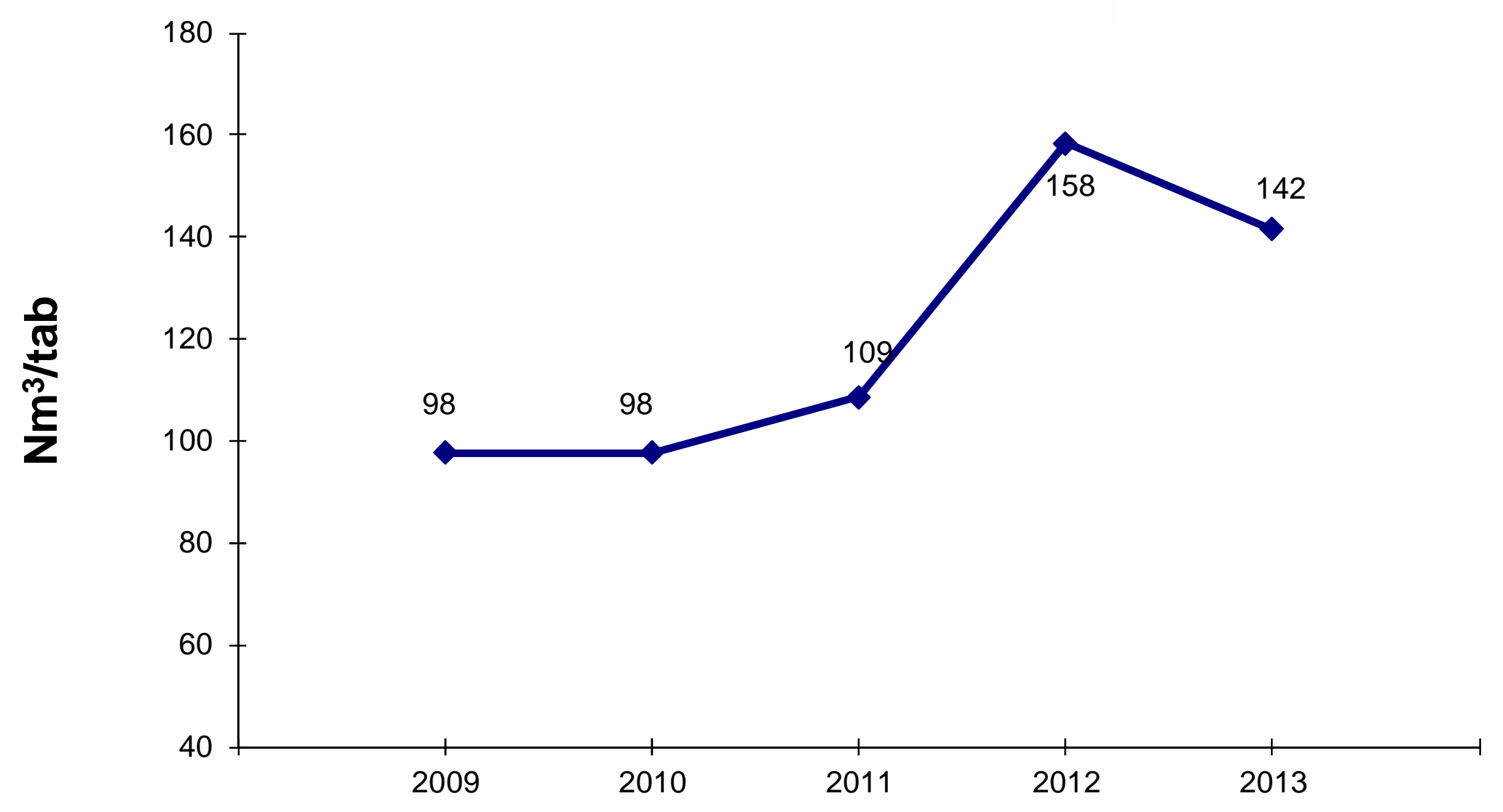

Queda no consumo de $\mathrm{N}_{2}$ devido menor consumo nos Afs, porém continua elevado devido a produção de aço em nível baixo. 


\section{Consumo de Nitrogênio por processo}

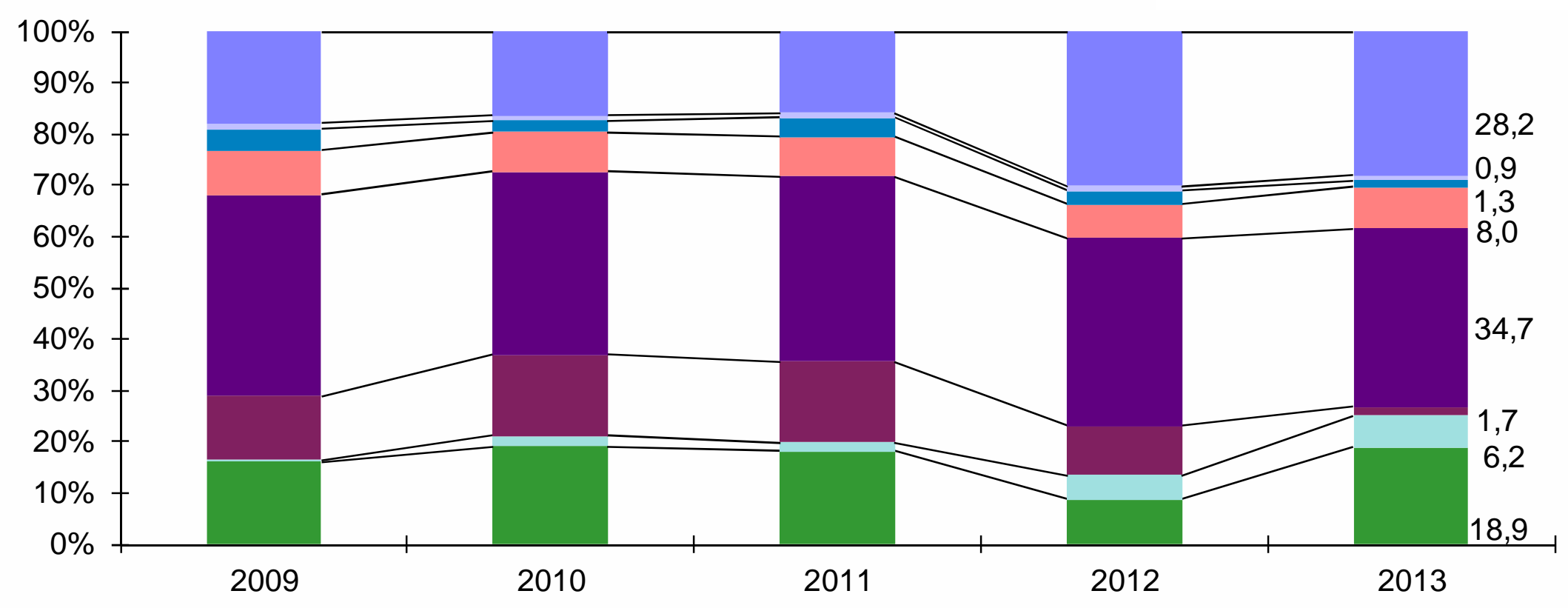

Alto Forno $1 \square$ Alto Forno $2 \square$ Alto Forno $3 \square$ Aciaria $\square$ Coqueria $\square$ Sistemas de Energia $\square$ Sinterização $\square$ Outros

-Sem comentários relevantes, ressaltando somente a parada do Alto Forno 3 e operação normal do Alto Forno 1 pós ano de reforma. 


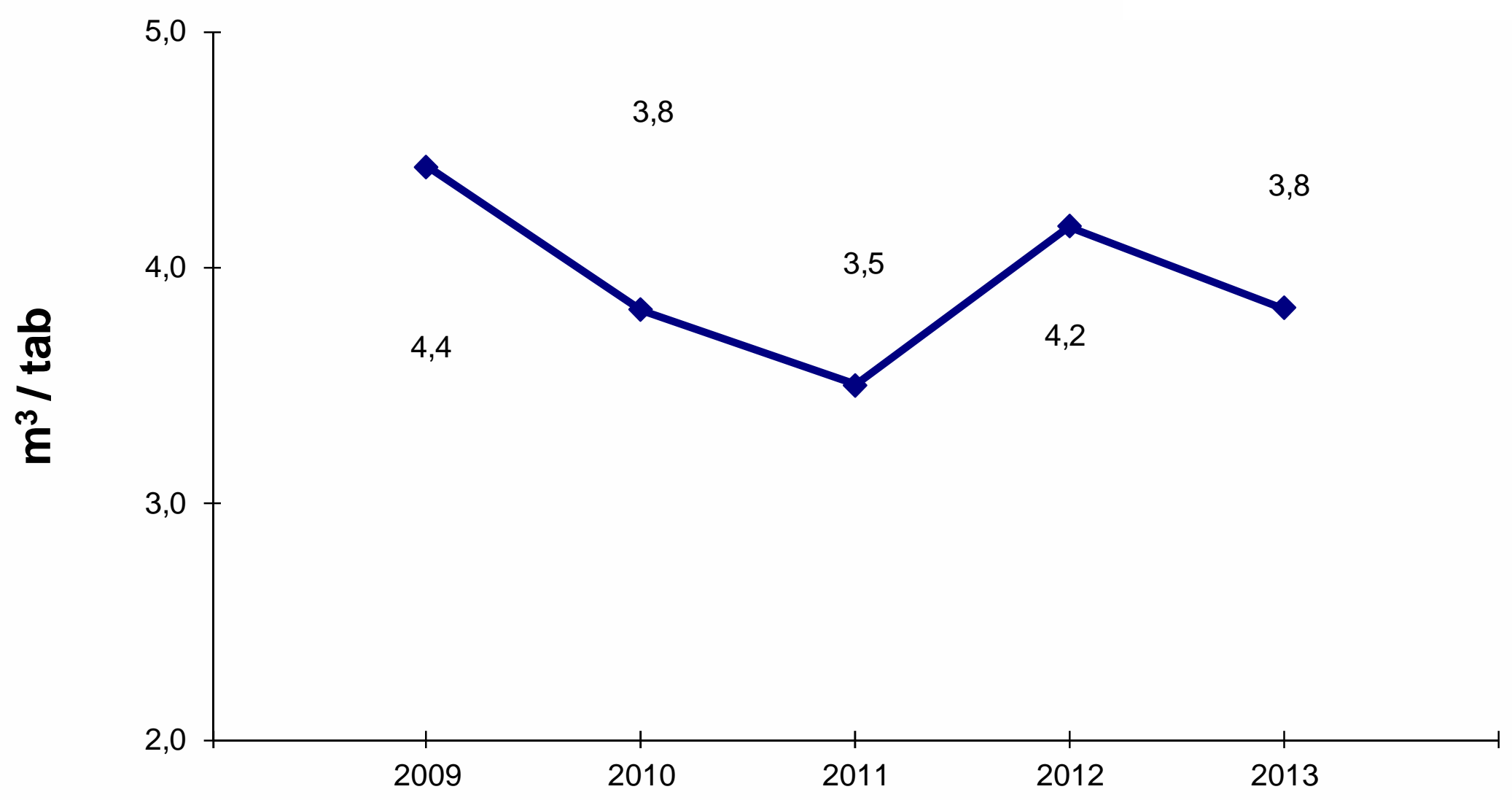

Sem comentários relevantes. Ano de operação normal. 


\section{Índice de Recirculação}

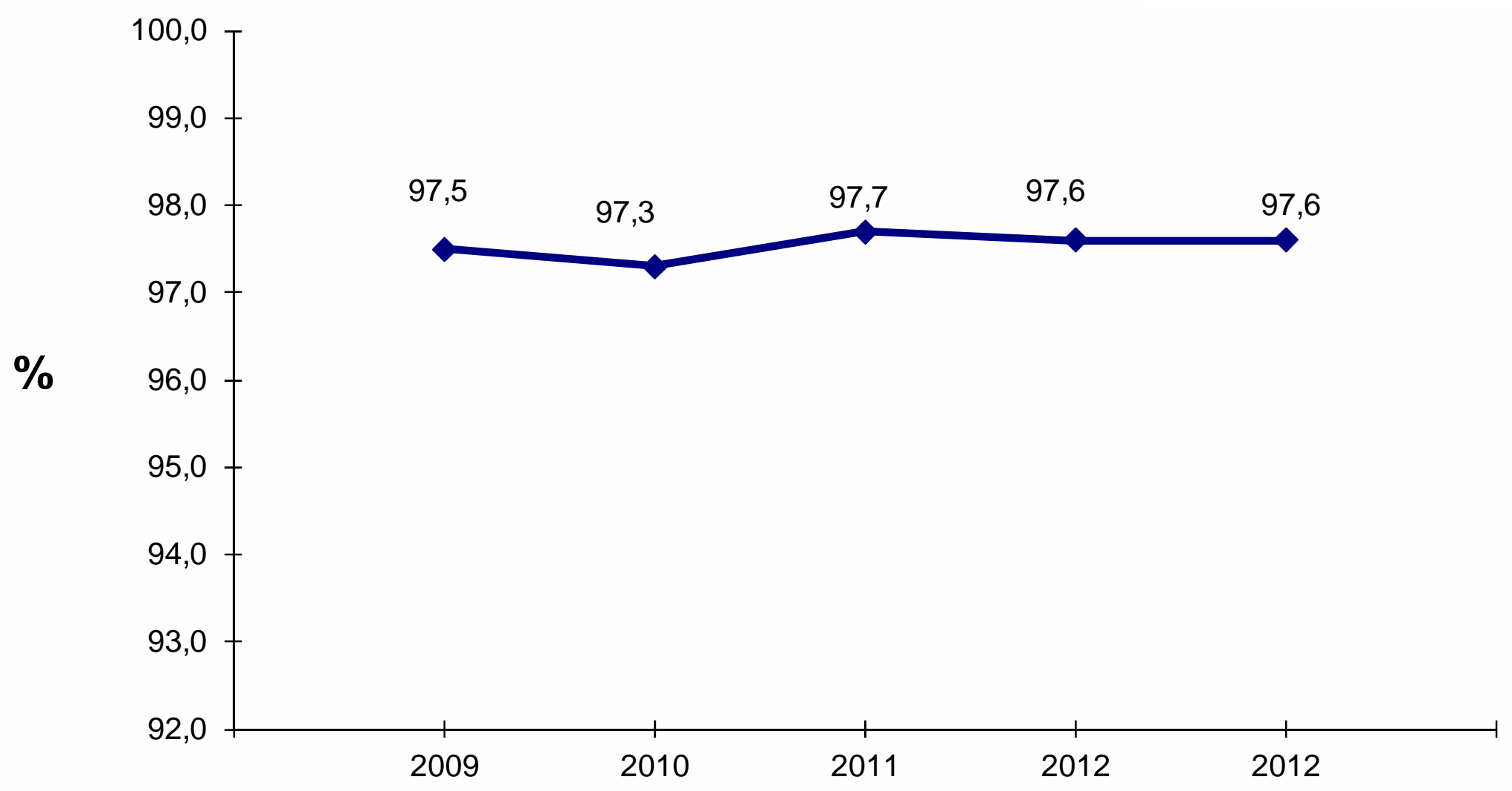

Sem comentários relevantes. Ano de operação normal. 


\section{Consumo de Água Doce por processo}

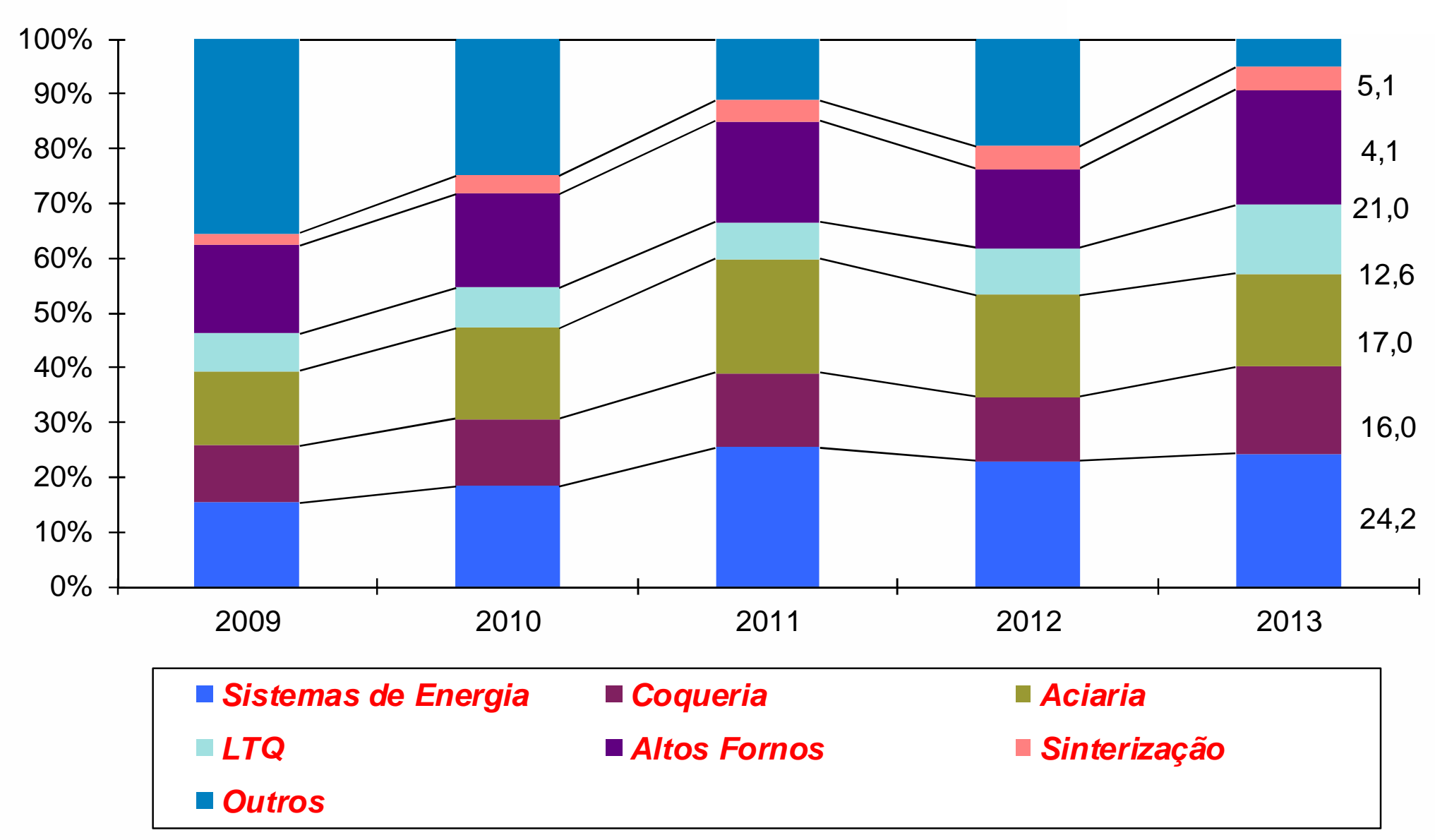

Sem comentários relevantes. 


\section{Consumo de Combustível para produção de Vapor}

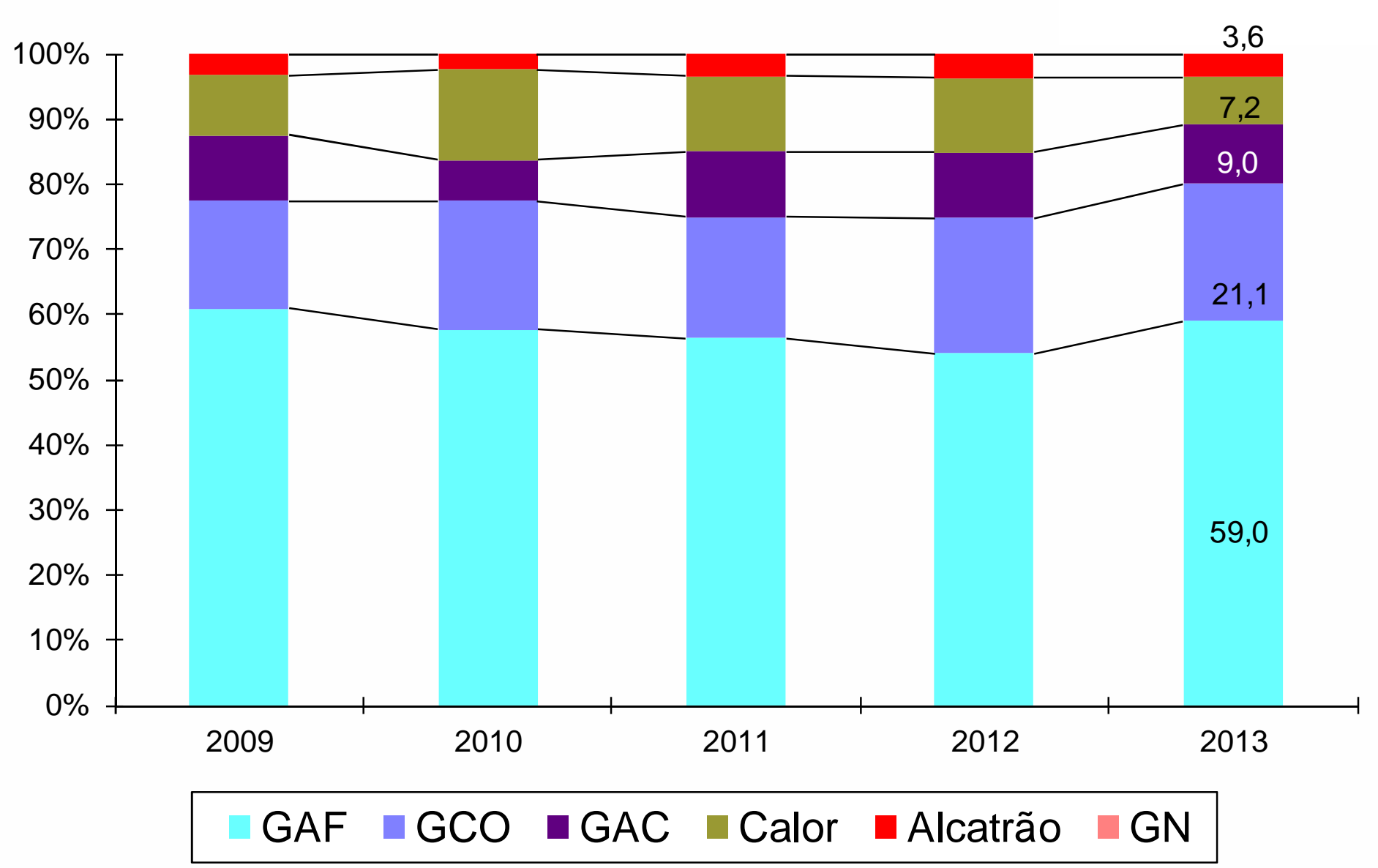

Sem comentários relevantes. 


\section{Fontes Energéticas}

\begin{tabular}{|c|c|c|c|c|}
\hline \multicolumn{5}{|c|}{2013} \\
\hline \multicolumn{2}{|r|}{ Fontes Energéticas } & Unidade & Gcal/unid. & GJ/unid. \\
\hline \multirow{18}{*}{ 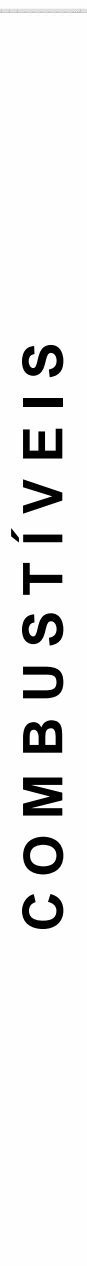 } & Carvão vegetal & $t$ & 7,0000000 & 29,3076000 \\
\hline & Carvão Met. Importado & $t$ & 7,6000000 & 31,8196800 \\
\hline & Carvão PCl & $t$ & 6,5000000 & 27,2142000 \\
\hline & Antracito & $\mathbf{t}$ & 6,5000000 & 27,2142000 \\
\hline & Coque Grosso & $t$ & 6,9000000 & 28,8889200 \\
\hline & Moinha de Coque (finos) & $t$ & 6,5000000 & 27,2142000 \\
\hline & Pó de CDQ & $\mathbf{t}$ & 6,5000000 & 27,2142000 \\
\hline & Alcatrão / Antraceno & $t$ & 8,8000000 & 36,8438400 \\
\hline & Gás de Coqueria & $\mathrm{Ndam}^{3}$ & 4,3856200 & 18,3617138 \\
\hline & Gás de Alto Forno & $\mathrm{Ndam}^{3}$ & 0,8296460 & 3,4735619 \\
\hline & Gás de Aciaria & $\mathrm{Ndam}^{3}$ & 2,0287800 & 8,4940961 \\
\hline & GLP & $\mathbf{t}$ & 12,0000000 & 50,2416000 \\
\hline & Gás Natural & Ndam $^{3}$ & 8,9000000 & 37,2625200 \\
\hline & Óleo combustivel & $\mathbf{t}$ & 10,0000000 & 41,8680000 \\
\hline & Óleo Diesel & $\mathbf{m}^{3}$ & 9,1910000 & 38,4808788 \\
\hline & Querosene & $\mathbf{m}^{3}$ & 9,1910000 & 38,4808788 \\
\hline & Gasolina & $\mathbf{m}^{3}$ & 8,2880000 & 34,7001984 \\
\hline & Álcool & $\mathbf{m}^{3}$ & 5,3800000 & 22,5249840 \\
\hline
\end{tabular}




\section{Utilidades e Matérias Primas}

\begin{tabular}{|c|c|c|c|c|}
\hline & UTILIDADES & Unidade & Gcal/unid. & GJ/unid. \\
\hline \multirow{15}{*}{$\begin{array}{l}\omega \\
w \\
0 \\
\varangle \\
0 \\
= \\
= \\
\square \\
\square\end{array}$} & Agua Bruta & dam $^{3}$ & 0,0000000 & 0,0000000 \\
\hline & Água Clarificada & dam $^{3}$ & 0,5126307 & 2,1462822 \\
\hline & Água Potável & dam $^{3}$ & 1,0746502 & 4,4993455 \\
\hline & Água Recirculada & dam $^{3}$ & 0,0000000 & 0,0000000 \\
\hline & Água Desmineralizada & dam $^{3}$ & 1,9777271 & 8,2803478 \\
\hline & Água do Mar & dam $^{3}$ & 0,3623191 & 1,5169576 \\
\hline & Energia Elétrica & MWh & $2,5000000^{\prime}$ & 10,4670000 \\
\hline & Ar Comprimido & $\mathrm{Ndam}^{3}$ & 0,3207950 & 1,3431045 \\
\hline & Oxigênio & Ndam $^{3}$ & 1,3331023 & 5,5814327 \\
\hline & Nitrogênio & $\mathrm{Ndam}^{3}$ & 1,3331023 & 5,5814327 \\
\hline & Argônio & $\mathrm{Ndam}^{3}$ & 1,3331023 & 5,5814327 \\
\hline & Vapor B. Pressão & $t$ & 0,6780000 & 2,8386504 \\
\hline & Vapor A. Pressão & $\mathbf{t}$ & 0,7596483 & 3,1804955 \\
\hline & Ar Soprado AF 1 e 3 e FOX 5 & $\mathrm{Ndam}^{3}$ & 0,2310759 & 0,9674686 \\
\hline & Ar Soprado AF2 e FOX 4 & $\mathrm{Ndam}^{3}$ & 0,2447155 & 1,0245749 \\
\hline \multirow{3}{*}{ MP } & Gusa Sólido & t & 3,0583633 & 12,8047554 \\
\hline & Sucata Comprada & $t$ & 3,0583633 & 12,8047554 \\
\hline & Vapor SOL Coqueria & $\mathbf{t}$ & 0,7596483 & 3,1804955 \\
\hline
\end{tabular}




\section{Consumo de fontes energéticas}

\begin{tabular}{|c|c|c|c|c|c|c|c|}
\hline COQUERIA & & 47.032 & $M J / t$ & SINTERIZACÃO & & 1.318 & $M J / t$ \\
\hline Fonte Energética & & Quantidade & GJ/ano & Fonte Energética & & Quantidade & GJ/ano \\
\hline Carvão Met. Importado & & 1.903 .072 & 60.555 .147 & Moinha de Coque (finos) & & 152.683 & 4.155 .146 \\
\hline Água Recirculada & & 20.000 & 0 & Energia Elétrica & & 229.337 & 2.400 .468 \\
\hline Gás de Coqueria & & 109.938 & 2.018 .650 & Gás de Coqueria & & 11.476 & 210.712 \\
\hline Vapor B. Pressão & & 177.916 & 505.040 & Pó de CDQ & & 1.745 & 47.483 \\
\hline Gás de Alto Forno & & 1.012 .919 & 3.518 .436 & Água Recirculada & & 0 & 0 \\
\hline Energia Elétrica & & 90.228 & 944.416 & Ar Comprimido & & 33.945 & 45.592 \\
\hline Nitrogênio & & 50.396 & 281.283 & Antracito & & 337 & 9.163 \\
\hline Água do Mar & & 50.282 & 76.276 & Água Clarificada & & 701 & 1.505 \\
\hline Ar Comprimido & & 42.933 & 57.663 & Nitrogênio & & 5.760 & 32.149 \\
\hline Água Desmineralizada & & 888 & 7.350 & Carvão vegetal & & 0 & 0 \\
\hline Água Clarificada & & 2.709 & 5.815 & Gás Natural & & 0 & 0 \\
\hline Produção (t) & : & 1.445 .193 & 67.970 .078 & Produção (t) & : & 5.237 .072 & 6.902 .217 \\
\hline & & & & & & & \\
\hline & & & & & & & \\
\hline ALTO FORNO 1 & & 17.296 & $M J / t$ & ALTO FORNO 2 & & 18.587 & $M J / t$ \\
\hline Fonte Energética & & Quantidade & GJ/ano & Fonte Energética & & Quantidade & GJ/ano \\
\hline Coque Grosso & & 1.214 .529 & 35.086 .433 & Coque Grosso & & 395.916 & 11.437 .587 \\
\hline Gás de Alto Forno & & 1.268 .240 & 4.405 .311 & Gás de Alto Forno & & 607.736 & 2.111 .009 \\
\hline Ar Soprado AF 1 e 3 e FOX 5 & & 3.218 .506 & 3.113 .804 & Ar Soprado AF2 e FOX 4 & & 1.090 .536 & 1.117 .336 \\
\hline Gás de Coqueria & & 101.353 & 1.861 .018 & Gás de Coqueria & & 35.478 & 651.437 \\
\hline Energia Elétrica & & 114.318 & 1.196 .567 & Energia Elétrica & & 53.786 & 562.982 \\
\hline Água do Mar & & 7.276 & 11.038 & Água do Mar & & 197 & 298 \\
\hline Vapor B. Pressão & & 28.295 & 80.319 & Vapor B. Pressão & & 13.666 & 38.792 \\
\hline Nitrogênio & & 118.710 & 662.569 & Nitrogênio & & 38.927 & 217.267 \\
\hline Água Desmineralizada & & 23 & 192 & Água Desmineralizada & & 2 & 19 \\
\hline Ar Comprimido & & 30.721 & 41.262 & Ar Comprimido & & 29.162 & 39.168 \\
\hline Alcatrão / Antraceno & & 0 & 0 & Alcatrão / Antraceno & & 0 & 0 \\
\hline Água Clarificada & & 2.212 & 4.747 & Água Clarificada & & 1.301 & 2.793 \\
\hline Antracito & & 0 & 0 & Antracito & & 0 & 0 \\
\hline Oxigênio & & 189.321 & 1.056 .683 & Oxigênio & & 50.169 & 280.012 \\
\hline Gás Natural & & 2.348 & 87.480 & Gás Natural & & 73 & 2.709 \\
\hline Carvão PCl & & 467.991 & 12.735 .993 & Carvão PCl & & 167.868 & 4.568 .395 \\
\hline Moinha de Coque (finos) & & 0 & 0 & Moinha de Coque (finos) & & 0 & 0 \\
\hline Produção (t) & : & 3.488 .823 & 60.343 .417 & Produção (t) & : & 1.131 .415 & 21.029 .804 \\
\hline
\end{tabular}




\section{Consumo de fontes energéticas}

\begin{tabular}{|c|c|c|c|c|c|c|c|}
\hline ALTO FORNO 3 & & \#DIV/0! & $M J / t$ & ACIARIA & & 2.457 & $M J / t$ \\
\hline Fonte Energética & & Quantidade & GJ/ano & Fonte Energética & & Quantidade & GJ/ano \\
\hline Coque Grosso & & 0 & 0 & Oxigênio & & 208.453 & 1.163 .466 \\
\hline Gás de Alto Forno & & 0 & 0 & Energia Elétrica & & 161.272 & 1.688 .030 \\
\hline Ar Soprado AF 1 e 3 e FOX 5 & & 0 & 0 & Nitrogênio & & 202.137 & 1.128 .214 \\
\hline Gás de Coqueria & & 0 & 0 & Moinha de Coque (finos) & & 0 & 0 \\
\hline Energia Elétrica & & 9.198 & 96.275 & Coque Grosso & & 0 & 0 \\
\hline Água do Mar & & 0 & 0 & Água Recirculada & & 0 & 0 \\
\hline Vapor B. Pressão & & 0 & 0 & Gás de Coqueria & & 0 & 0 \\
\hline Nitrogênio & & 10.372 & 57.890 & Ar Comprimido & & 26.149 & 35.120 \\
\hline Água Desmineralizada & & 0 & 1 & Água do Mar & & 3.504 & 5.315 \\
\hline Ar Comprimido & & 35.040 & 47.062 & Água Clarificada & & 1.726 & 3.705 \\
\hline Alcatrão / Antraceno & & 0 & 0 & Água Desmineralizada & & 135 & 1.116 \\
\hline Água Clarificada & & 53 & 114 & Sucata Comprada & & 477.933 & 6.119 .819 \\
\hline Antracito & & 0 & 0 & Gusa Sólido & & 0 & 0 \\
\hline Oxigênio & & 0 & 0 & Gás Natural & & 10.936 & 407.486 \\
\hline Gás Natural & & 579 & 21.557 & Vapor B. Pressão & & 157.943 & 448.344 \\
\hline Carvão PCl & & 0 & 0 & Argônio & & 6.410 & 35.777 \\
\hline Moinha de Coque (finos) & & 0 & 0 & & & & \\
\hline Produção (t) & : & 0 & 222.899 & Produção (t) & : & 4.491 .854 & 11.036 .393 \\
\hline LING. CONTÍNUO & & 253 & $M J / t$ & & & & \\
\hline Fonte Energética & & Quantidade & GJ/ano & & & & \\
\hline & & & & & & & \\
\hline Oxigênio & & 0 & 0 & & & & \\
\hline Energia Elétrica & & 74.372 & 778.456 & & & & \\
\hline Ar Comprimido & & 119.294 & 160.224 & & & & \\
\hline Água Clarificada & & 1.135 & 2.435 & & & & \\
\hline Nitrogênio & & 8.655 & 48.307 & & & & \\
\hline Gás Natural & & 3.555 & 132.477 & & & & \\
\hline GLP & & 0 & 0 & & & & \\
\hline Água Recirculada & & 0 & 0 & & & & \\
\hline Argônio & & 0 & 0 & & & & \\
\hline Produção (t) & : & 4.429 .659 & 1.121 .899 & & & & \\
\hline
\end{tabular}




\section{Consumo de fontes energéticas}

\begin{tabular}{|c|c|c|c|c|c|c|c|}
\hline CALCINACÃO 1 & & \#DIV/0! & $M J / t$ & CALCINACCÃO 2 & & 4.527 & $M J / t$ \\
\hline Fonte Energética & & Quantidade & GJ/ano & Fonte Energética & & Quantidade & GJ/ano \\
\hline Energia Elétrica & & 4.030 & 42.178 & Gás de Alto Forno & & 0 & 0 \\
\hline Ar Comprimido & & 2.000 & 2.686 & Gás de Aciaria & & 106.697 & 906.293 \\
\hline Água Clarificada & & 0 & 0 & Gás Natural & & 0 & 0 \\
\hline & & & & Água Clarificada & & 18 & 38 \\
\hline \multirow[t]{2}{*}{ Produção (t) } & : & 0 & 44.864 & Ar Comprimido & & 0 & 0 \\
\hline & & & & Produção (t) & : & 241.268 & 1.092 .151 \\
\hline$\underline{L T Q}$ & & 2.401 & $M J / t$ & CONDICIONAMENTO & & 698 & $M J / t$ \\
\hline Gás de Alto Forno & & 132.539 & 460.382 & Oxigênio & & 0 & 0 \\
\hline Gás Natural & & 2.917 & 108.685 & Gás Natural & & 42 & 1.570 \\
\hline Gás de Aciaria & & 108.274 & 919.686 & Ar Comprimido & & 0 & 0 \\
\hline Ar Comprimido & & 11.528 & 15.484 & Óleo Diesel & & 0 & 0 \\
\hline Nitrogênio & & 0 & 0 & Água Clarificada & & 738 & 1.584 \\
\hline Água Clarificada & & 2.131 & 4.574 & Vapor B. Pressão & & 0 & 0 \\
\hline & & & & & & & \\
\hline Produção (t) & : & 3.726 .871 & 8.947 .004 & Produção (t) & : & 428.715 & 299.316 \\
\hline
\end{tabular}




\section{Consumo de fontes energéticas}

\begin{tabular}{|c|c|c|c|c|c|c|c|}
\hline C.A. PRESSÃO & & 2.888 & $M J / t$ & FRAC. DE AR & & 5.168 & $M J / t$ \\
\hline Fonte Energética & & Quantidade & GJ/ano & Fonte Energética & & Quantidade & GJ/ano \\
\hline Gás de Alto Forno & & 3.373 .213 & 11.717 .065 & Energia Elétrica & & 576.671 & 6.036 .013 \\
\hline Gás de Coqueria & & 228.198 & 4.190 .106 & Água Recirculada & & 0 & 0 \\
\hline Vapor B. Pressão & & 52.385 & 148.702 & Nitrogênio & & 6.990 & 39.017 \\
\hline Energia Elétrica & & 98.024 & 1.026 .021 & Ar Comprimido & & 11.773 & 15.813 \\
\hline Alcatrão / Antraceno & & 19.671 & 724.740 & Água Potável & & 526 & 2.365 \\
\hline Querosene & & 0 & 0 & Vapor B. Pressão & & 17.520 & 49.733 \\
\hline Água Desmineralizada & & 312 & 2.584 & Água Clarificada & & 446 & 957 \\
\hline Ar Comprimido & & 5.000 & 6.716 & Água Desmineralizada & & 0 & 0 \\
\hline Nitrogênio & & 1.200 & 6.698 & Ar Soprado AF2 e FOX 4 & & 0 & 0 \\
\hline Água do Mar & & 68.217 & 103.482 & Ar Soprado AF 1 e 3 e FOX 5 & & 0 & 0 \\
\hline Gás Natural & & 0 & 0 & & & & \\
\hline \multirow{2}{*}{ Gás de Aciaria } & & 211.379 & 1.795 .472 & & & & \\
\hline & & & & Produção (NDam³) & : & 1.188 .815 & 6.143 .898 \\
\hline \multirow[t]{3}{*}{ Produção (t) } & : & 6.827 .652 & 19.721 .587 & & & & 5,168087081 \\
\hline & & & & & & & \\
\hline & & & & GERADORES & & 11.883 & $M J / M W h$ \\
\hline \multirow[t]{2}{*}{ COMPRESSORES } & & 1.347 & $\mathrm{MJ} / \mathrm{Nm}^{3}$ & & & & \\
\hline & & & & Fonte Energética & & Quantidade & GJ/ano \\
\hline \multirow[t]{2}{*}{ Fonte Energética } & & Quantidade & GJ/ano & & & & \\
\hline & & & & Vapor A. Pressão & & 5.274 .183 & 16.774 .514 \\
\hline Energia Elétrica & & $62.897^{*}$ & 658.341 & Água do Mar & & 231.603 & 351.332 \\
\hline Água Recirculada & & 0 & 0 & Óleo Diesel & & 0 & 0 \\
\hline & & & & & & & \\
\hline Produção (NDam³) & : & 488.712 & 658.341 & Produção (MWh) & : & 1.441 .191 & 17.125 .846 \\
\hline
\end{tabular}




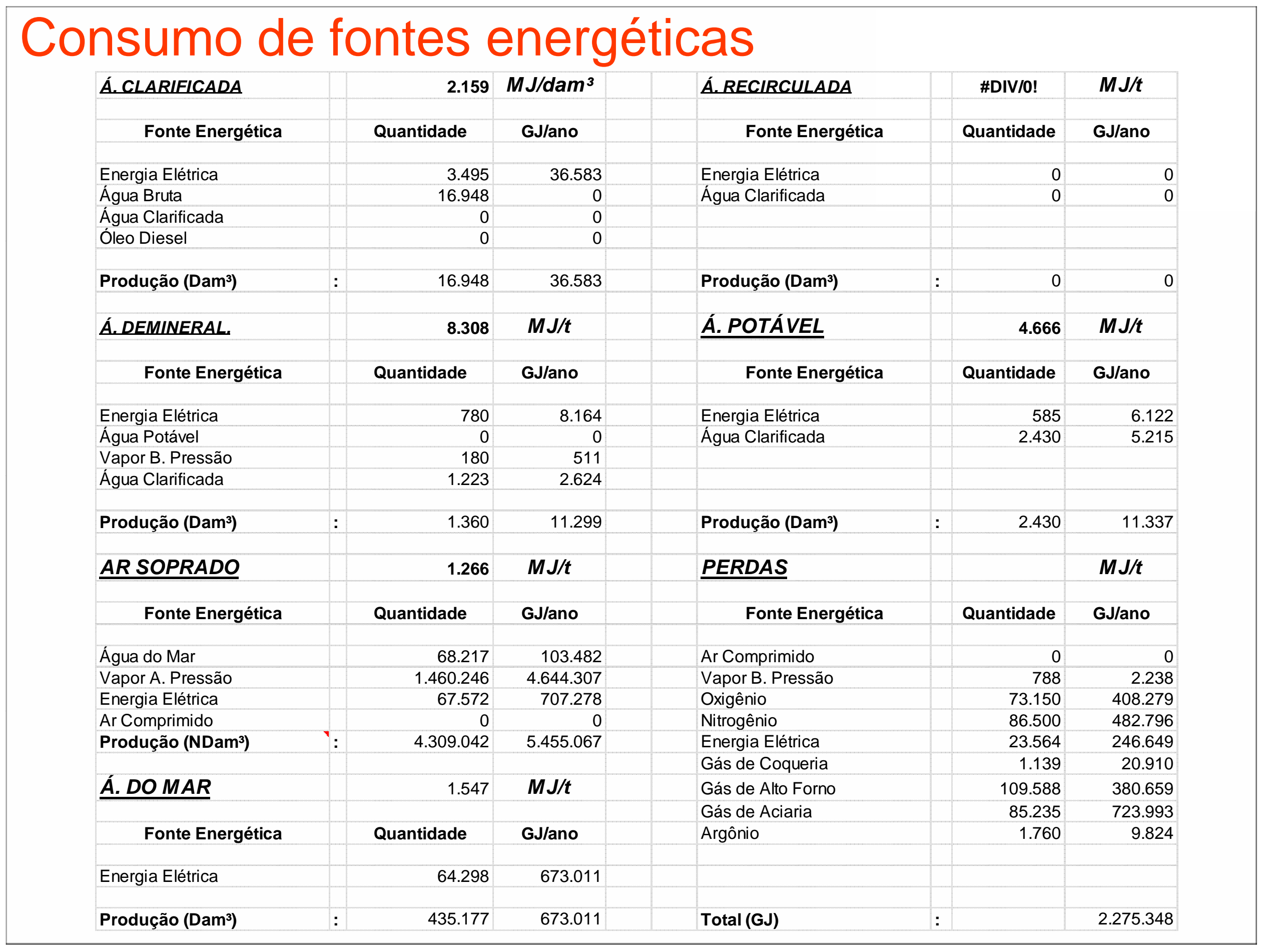




\section{Consumo de fontes energéticas}

\begin{tabular}{|c|c|c|c|c|c|c|}
\hline DISTRIBUIÇÃOO & & $M J / t$ & OUTROS & & & $M J / t$ \\
\hline Fonte Energética & Quantidade & GJ/ano & Fonte Energética & & Quantidade & GJ/ano \\
\hline Oxigênio & 0 & 0 & Energia Elétrica & & 47.437 & 496.525 \\
\hline Energia Elétrica & 0 & 0 & Gás de Coqueria & & 18.133 & 332.957 \\
\hline Nitrogênio & 0 & 0 & Vapor B. Pressão & & 56.735 & 161.050 \\
\hline Gás de Coqueria & 0 & 0 & Óleo Diesel & & 6.076 & 233.795 \\
\hline Gás de Alto Forno & 0 & 0 & Ar Comprimido & & 135.911 & 182.542 \\
\hline Óleo Diesel & 63 & 2.416 & Água Potável & & 2.430 & 10.932 \\
\hline Água Recirculada & 0 & 0 & Oxigênio & & 8.567 & 47.818 \\
\hline \multirow[t]{3}{*}{ Vapor B. Pressão } & 10.800 & 30.657 & Nitrogênio & & 90.145 & 503.136 \\
\hline & & & Álcool & & 0 & 0 \\
\hline & & & Água Recirculada & & 0 & 0 \\
\hline \multirow[t]{2}{*}{ FUNDICÃO } & 0 & $M J / t$ & Água Clarificada & & 38 & 81 \\
\hline & & & Querosene & & 0 & 0 \\
\hline \multirow[t]{2}{*}{ Fonte Energética } & Quantidade & GJ/ano & Gás de Alto Forno & & 0 & 0 \\
\hline & & & Gás Natural & & 11.300 & 421.065 \\
\hline Ar Comprimido & 5.256 & 7.059 & Gasolina & & 235 & 8.168 \\
\hline Energia Elétrica & 0 & 0 & Água Desmineralizada & & 0 & 0 \\
\hline Gás Natural & 115 & 4.286 & Vapor A. Pressão & & 0 & 0 \\
\hline Vapor B. Pressão & 0 & 0 & & & & \\
\hline Oxigênio & 0 & 0 & & & & \\
\hline Água Potável & 0 & 0 & & & & \\
\hline Água Clarificada & 88 & 188 & & & & \\
\hline Produção (t) & 0 & 11.533 & Total (GJ) & : & & 2.398.069 \\
\hline
\end{tabular}




\section{Consumo de fontes energéticas}

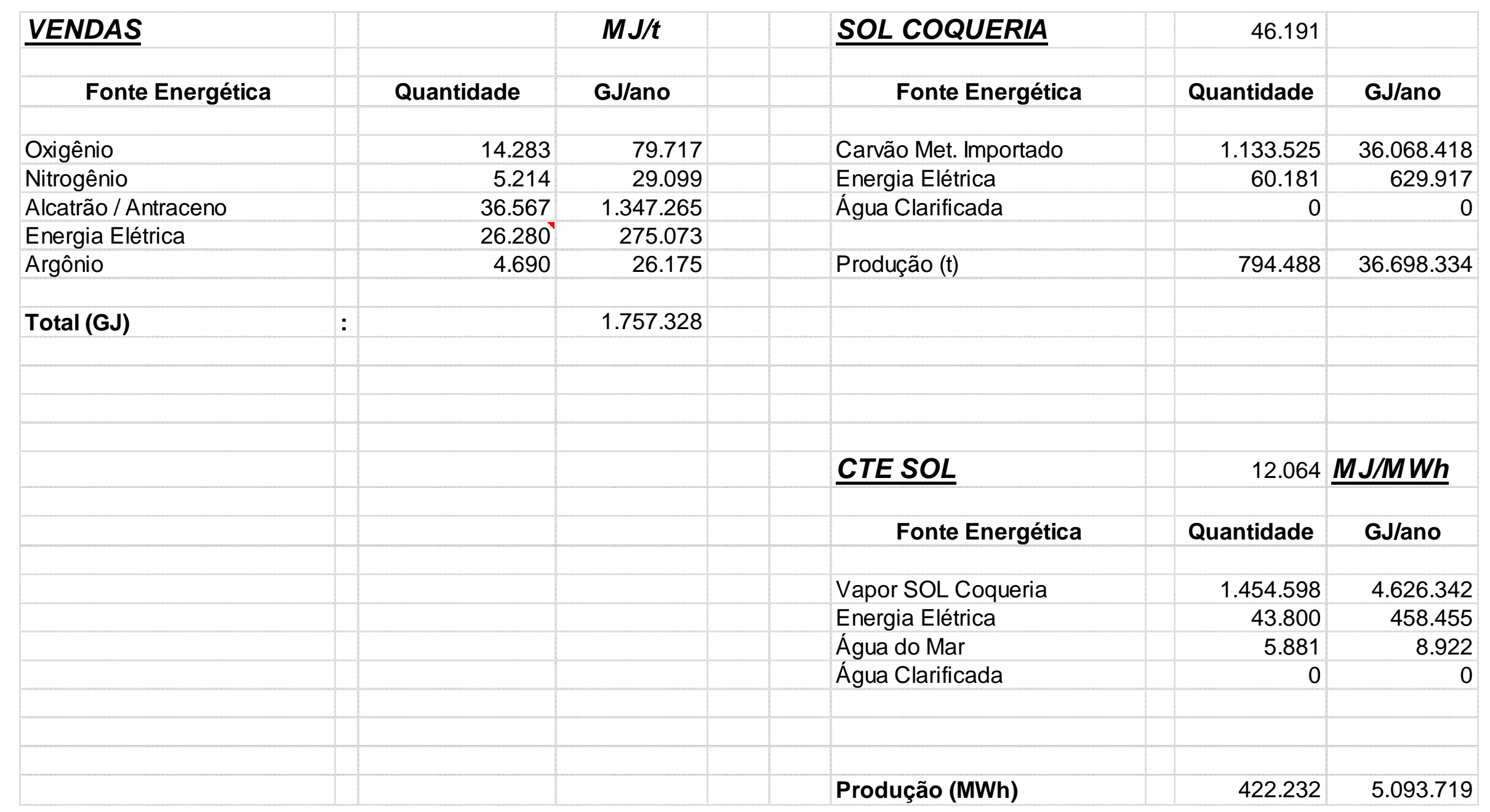




\section{Sistema de equações para cálculo de equivalentes energéticos}

SISTEMA DE EQUAÇÕES PARA CÁLCULO DOS EQUIVALENTES DAS UTILIDADES

$$
2013
$$

\begin{tabular}{|c|c|c|c|c|c|c|c|c|c|c|c|c|c|c|c|c|c|c|c|c|c|c|c|c|c|c|c|}
\hline & & & & & & & & & & & & & & & & & & & & & & & & & Gcal & GJ & $\mathrm{KW}$ \\
\hline ÁGUA BRUTA & 16.948 & A & $=$ & & & & & & & & & & & & & & & & & & & & A & dam $^{3}$ & 0,0000 & 0,0000 & \\
\hline ÁGUA CLARIFICADA & 16.948 & B & $=$ & 16.948 & $x$ & A & + & 3.495 & $\mathrm{x}$ & 2,5 & & & & & & & & & & & & & B & $\mathrm{dam}^{3}$ & 0,5156 & 2,1586 & 206,228 \\
\hline ÁGUA POTÁVEL & 2.955 & C & $=$ & 2.430 & $x$ & B & + & 585 & $\mathrm{x}$ & 2,5 & & & & & & & & & & & & & C & $\mathrm{dam}^{3}$ & 0,9163 & 3,8362 & 366,5 \\
\hline ÁGUA RECIRCULADA & 20.000 & D & $=$ & 0 & $\mathrm{x}$ & B & + & 0 & $\mathrm{x}$ & 2,5 & & & & & & & & & & & & & D & dam $^{3}$ & 0,0000 & 0,0000 & 0,0 \\
\hline Á. DESMINERALIZADA & 1.360 & E & $=$ & 1.223 & $\mathrm{x}$ & B & + & 780 & $\mathrm{x}$ & 2,5 & + & 180 & $\mathrm{x}$ & I & & & & & & & & & E & dam $^{3}$ & 1,9843 & 8,3079 & 793,7 \\
\hline ÁGUA DO MAR & 435.177 & $\mathbf{F}$ & $=$ & & & & 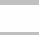 & 64.298 & $\mathrm{x}$ & 2,5 & & & & & & & & & & & & & $\mathbf{F}$ & dam $^{3}$ & 0,3694 & 1,5465 & 147,8 \\
\hline AR COMPRIMIDO & 488.712 & G & $=$ & 0 & $\mathrm{x}$ & D & + & 62.897 & $\mathrm{x}$ & 2,5 & & & & & & & & & & & & & G & $\mathrm{Ndam}^{3}$ & 0,3217 & 1,3471 & 128,7 \\
\hline OXIGÊNIO/NITROGÊNIO & 1.188 .815 & H & $=$ & 0 & $\mathrm{x}$ & D & + & 576.671 & $\mathrm{x}$ & 2,5 & + & 525,6 & $\mathrm{x}$ & C & + & 11.773 & $x$ & G & + & 17.520 & $\mathrm{x}$ & I & H & $\mathrm{Ndam}^{3}$ & 1,2344 & 5,1681 & 493,8 \\
\hline VAPOR A.P. & 6.734 .429 & I & $=$ & 5.000 & $x$ & G & + & 98.024 & $\mathrm{x}$ & 2,5 & + & 1.200 & $x$ & H & + & 52.385 & $x$ & I & + & 19.671 & $x \varepsilon$ & 8,8 & 1 & $\mathbf{t}$ & 0,7014 & 2,9364 & 280,5 \\
\hline & & & & 312 & $x$ & E & + & 3.373 .213 & $x$ & GAF & + & 228.198 & $\mathrm{x}$ & GCO & + & 0 & $\mathrm{x}$ & 9 & & & & & & & & & \\
\hline AR SOPRADO AF 1 & 3.218 .506 & $\mathbf{J}$ & $=$ & 68.217 & $\mathrm{x}$ & $\mathbf{F}$ & + & 1.460 .246 & $\mathrm{x}$ & I & & & & & & & & & & & & & $\mathbf{J}$ & $\mathrm{Ndam}^{3}$ & 0,3523 & 1,4752 & 140,9 \\
\hline AR SOPRADO AF 2 & 1.090 .536 & K & $=$ & 67.572 & $x$ & & 2.5 & & & & & & & & & & & & & & & & K & $\mathrm{Ndam}^{3}$ & 0.1549 & 0.6486 & 62.0 \\
\hline
\end{tabular}




\section{Balanço Energético Simplificado}

\begin{tabular}{|c|c|c|c|c|}
\hline \multicolumn{4}{|c|}{ BALANÇO ENERGÉTICO GLOBAL SIMPLIFICADO } & 2013 \\
\hline Fontes Energéticas & Unid. & GJ/unid. & Quantidade & GJ \\
\hline Carvão Met. Importado & $t$ & 31,8 & 3.036 .598 & 96.623 .565 \\
\hline Carvão PCl & $\mathrm{t}$ & 27,2 & 635.859 & 17.304 .387 \\
\hline Antracito & $t$ & 27,2 & 337 & 9.163 \\
\hline Coque Grosso & $t$ & 28,9 & 1.610 .445 & 46.524 .020 \\
\hline Moinha de Coque (finos) & $\mathrm{t}$ & 27,2 & 152.683 & 4.155 .146 \\
\hline Pó de CDQ & $\mathrm{t}$ & 27,2 & 1.745 & 47.483 \\
\hline Energia Elétrica & $\mathrm{MWh}$ & 10,5 & 2.168 .133 & 22.693 .844 \\
\hline GLP & $t$ & 50,2 & 0 & 0 \\
\hline Gás Natural & Ndam $^{3}$ & 37,3 & 31.864 & 1.187 .316 \\
\hline Óleo Diesel & $m^{3}$ & 38,5 & 6.138 & 236.211 \\
\hline Álcool & $\mathrm{m}^{3}$ & 22,5 & 0 & 0 \\
\hline Querosene & $m^{3}$ & 38,5 & 0 & 0 \\
\hline Gasolina & $\mathrm{m}^{3}$ & 34,7 & 235 & 8.168 \\
\hline Alcatrão / Antraceno & $\mathrm{t}$ & 36,8 & 19.671 & 724.740 \\
\hline \multicolumn{4}{|c|}{ SUB TOTAL } & 189.514 .044 \\
\hline Coque Grosso & $t$ & 28,9 & 2.001 .155 & 57.811 .206 \\
\hline Moinha de Coque (finos) & $\mathrm{t}$ & 27,2 & 238.526 & 6.491 .295 \\
\hline Pó de CDQ & $\mathrm{t}$ & 27,2 & 0 & 0 \\
\hline Alcatrão / Antraceno & $\mathrm{t}$ & 36,8 & 56.238 & 2.072 .005 \\
\hline Oxigênio & $\mathrm{Ndam}^{3}$ & 5,6 & 14.283 & 79.717 \\
\hline Nitrogênio & Ndam $^{3}$ & 5,6 & 5.214 & 29.099 \\
\hline Argônio & $\mathrm{Ndam}^{3}$ & 5,6 & 4.690 & 26.175 \\
\hline Energia Elétrica & $\mathrm{MWh}$ & 10,5 & 1.987 .289 & 20.800 .957 \\
\hline SUB TOTAL & \multicolumn{3}{|c|}{ SUB TOTAL } & 87.310 .454 \\
\hline \multicolumn{4}{|c|}{ BALANCO } & 102.203 .590 \\
\hline
\end{tabular}

\section{Consumo de Energia por Tonelada de Placas}

Produção de placas: 


\section{Balanço de Combustíveis}

BALANÇO DE COMBUSTÍVEIS

MJ / t (placas)

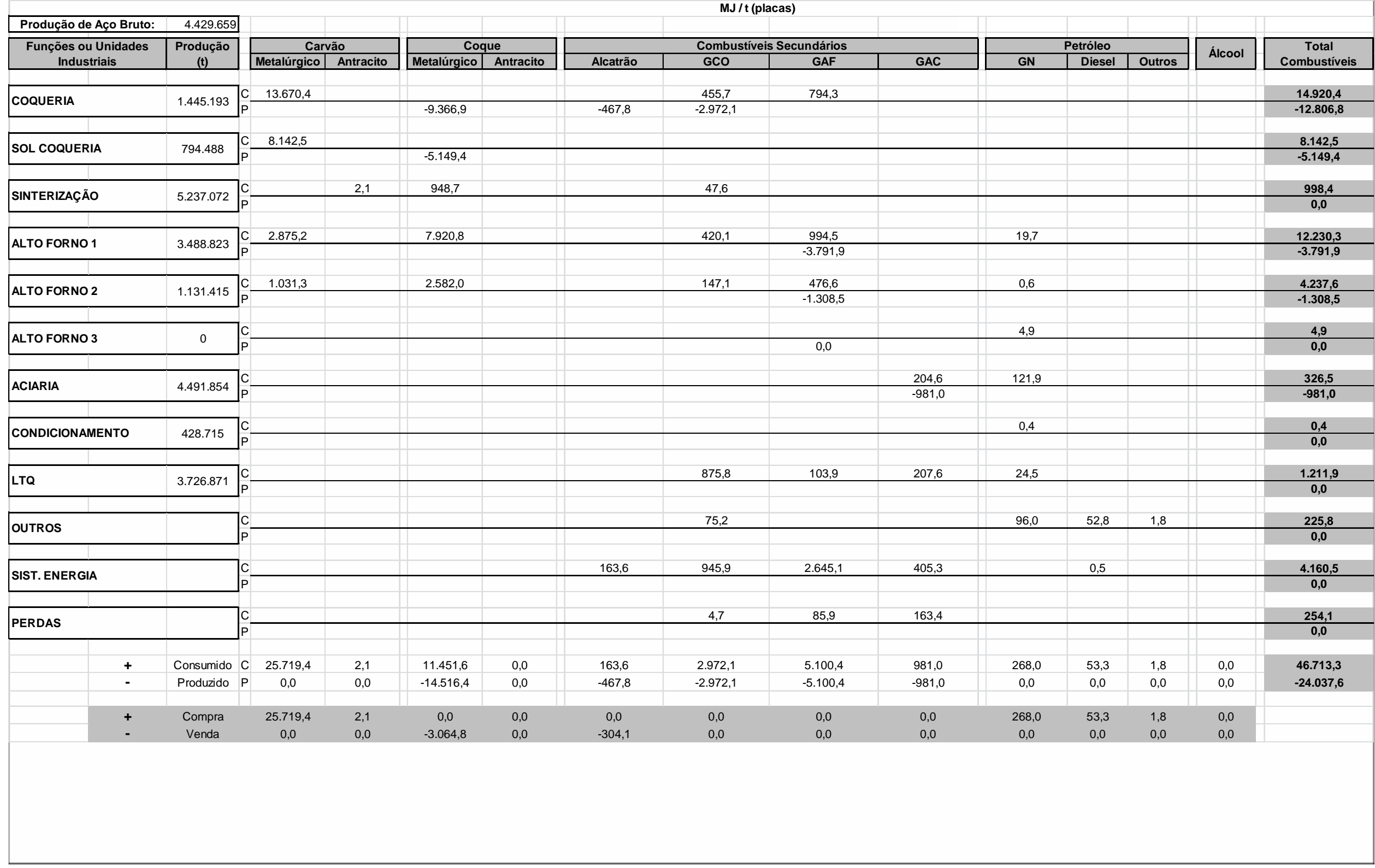




\section{Balanço de Utilidades}

\section{BALANÇO DE UTILIDADES}

\begin{tabular}{|c|c|c|c|c|c|c|c|c|c|c|c|c|c|c|}
\hline \multirow{2}{*}{ Produção de Aço Bruto: } & \multicolumn{14}{|c|}{ MJ / t (placas) } \\
\hline & 4.429 .659 & & & & & & & & & & & & & \\
\hline \multirow{2}{*}{$\begin{array}{c}\begin{array}{c}\text { Funções ou Unidades } \\
\text { Industriais }\end{array} \\
\end{array}$} & \begin{tabular}{|l|} 
Produção \\
\end{tabular} & Energia & \multirow{2}{*}{\multicolumn{4}{|c|}{\begin{tabular}{|c|c|c|}
\multicolumn{2}{c}{ Água } \\
Potável & Desmi
\end{tabular}}} & \multirow{2}{*}{$\begin{array}{c}\mathrm{Ar} \\
\text { comprimido }\end{array}$} & \multirow{2}{*}{ Ar Soprado } & \multicolumn{3}{|c|}{ Gases do $\mathrm{Ar}$} & \multicolumn{2}{|c|}{ Vapor } & \multirow{2}{*}{$\begin{array}{c}\text { Total de } \\
\text { Utilidades }\end{array}$} \\
\hline & (t) & Elétrica & & & & & & & 02 & N2 & Argônio & AP & $B P$ & \\
\hline \multirow{2}{*}{ COQUERIA } & 1445193 & 213,2 & 1,3 & & 1,7 & 17,2 & 13,0 & & & 63,5 & & & 114,0 & 424 \\
\hline & 1.445 .193 & $\mathrm{P}$ & & & & & & & & & & & $-259,6$ & -260 \\
\hline \multirow{2}{*}{ SOL COQUERIA } & & 142,2 & & & & & & & & & & & & 142 \\
\hline & 794.488 & $\mathrm{P}$ & & & & & & & & & & $-1.044,4$ & & -1.044 \\
\hline \multirow{2}{*}{ SINTERIZAÇÃO } & & 541,9 & 0,3 & & & & 10,3 & & & 7,3 & & & & 560 \\
\hline & 5.237 .072 & $\mathrm{P}$ & & & & & & & & & & & & 0 \\
\hline \multirow{2}{*}{ ALTO FORNO 1} & 3488823 & 270,1 & 1,1 & & 0,0 & 2,5 & 9,3 & 702,9 & 238,5 & 149,6 & & & 18,1 & 1.392 \\
\hline & 3.488 .823 & $-292,7$ & & & & & & & & & & & & -293 \\
\hline \multirow{2}{*}{ ALTO FORNO 2} & 1.131 .415 & 127,1 & 0,6 & & 0,0 & 0,1 & 8,8 & 252,2 & 63,2 & 49,0 & & & 8,8 & 510 \\
\hline & 1.101 .410 & $\mathrm{P}$ & & & & & & & & & & & & 0 \\
\hline \multirow{2}{*}{ ALTO FORNO 3} & 0 & 21,7 & 0,0 & & 0,0 & 0,0 & 10,6 & 0,0 & 0,0 & 13,1 & & & 0,0 & 45 \\
\hline & 0 & $\mathrm{P}$ & & & & & & & & & & & & 0 \\
\hline \multirow{2}{*}{ ACIARIA } & 4491854 & 599,5 & 1,4 & & 0,3 & 1,2 & 44,7 & & 262,7 & 274,4 & 8,1 & & 101,2 & 1.293 \\
\hline & 4.491 .854 & $\mathrm{P}$ & & & & & & & & & & & & 0 \\
\hline \multirow{2}{*}{ CONDICIONAMENTO } & & 66,9 & 0,4 & & & & & & & & & & & 67 \\
\hline & 428.715 & $\mathrm{P}$ & & & & & & & & & & & & 0 \\
\hline \multirow[b]{2}{*}{ LTQ } & & 803,3 & 1,0 & & & & 3,5 & & & & & & & 808 \\
\hline & 3.726 .871 & $P$ & & & & & & & & & & & & 0 \\
\hline \multirow{2}{*}{ OUTROS } & & 112,1 & 0,1 & 2,5 & & & 42,8 & & 10,8 & 113,6 & & & 36,4 & 318 \\
\hline & & $\mathrm{P}$ & & & & & & & & & & & & 0 \\
\hline \multirow{2}{*}{ SIST. ENERGIA } & & $2.169,5$ & 2,0 & 0,5 & 0,6 & 128,0 & 5,1 & 0,0 & & 10,3 & & $5.879,7$ & 51,8 & 8.248 \\
\hline & & $\begin{array}{ll}\text { P } & -4.403,1\end{array}$ & $-8,2$ & $-2,5$ & $-2,5$ & $-149,0$ & $-148,2$ & $-955,2$ & $\begin{array}{l}-685,4 \\
\end{array}$ & $-796,3$ & $-16,2$ & $\begin{array}{c}-4.835,3 \\
\end{array}$ & $\begin{array}{c}71,2 \\
\end{array}$ & -12.073 \\
\hline \multirow{2}{*}{ PERDAS } & & 55,7 & & & & & & & 92,2 & 109,0 & 2,2 & & 0,5 & 260 \\
\hline & & $\mathrm{P}$ & & & & & & & & & & & & 0 \\
\hline+ & Consumido & $5.123,2$ & 8,2 & 3,0 & 2,5 & 149,0 & 148,2 & 955,2 & 667,4 & 789,8 & 10,3 & $5.879,7$ & 330,8 & $14.067,3$ \\
\hline - & Produzido & $-4.695,8$ & $-8,2$ & $-2,5$ & $-2,5$ & $-149,0$ & $-148,2$ & $-955,2$ & $-685,4$ & $-796,3$ & $-16,2$ & $-5.879,7$ & $-330,8$ & $(13.669,9)$ \\
\hline+ & Compra & 427,3 & 0,0 & 0,5 & 0,0 & 0,0 & 0,0 & 0,0 & 0,0 & 0,0 & 0,0 & 0,0 & 0,0 & 397,4 \\
\hline - & Venda & 0,0 & 0,0 & 0,0 & 0,0 & 0,0 & 0,0 & 0,0 & $-18,0$ & $-6,6$ & $-5,9$ & 0,0 & 0,0 & 0,0 \\
\hline
\end{tabular}




\section{Balanço Global}

\section{BALANÇO GLOBAL}

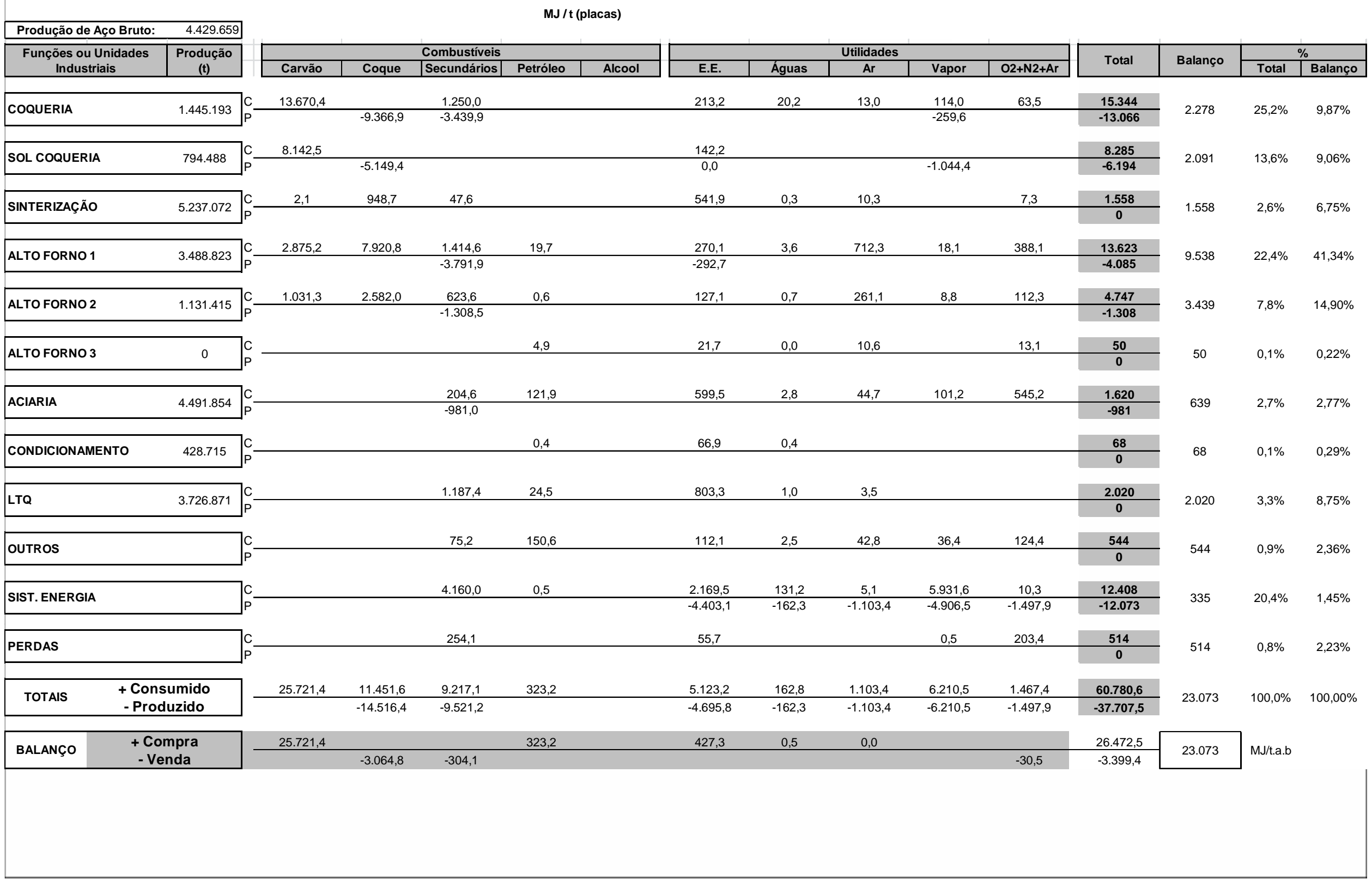




\section{ArcelorMittal}

\section{FIM}

Gustavo Ludgero

Especialista em Energia e Utilidades

gustavo.ludgero@arcelormittal.com.br

+552733482751 